\title{
North Atlantic warming: patterns of long-term trend and multidecadal variability
}

\author{
Igor V. Polyakov $\cdot$ Vladimir A. Alexeev • \\ Uma S. Bhatt · Evgenia I. Polyakova • \\ Xiangdong Zhang
}

Received: 5 August 2008/Accepted: 17 December 2008/Published online: 10 January 2009

(C) The Author(s) 2009. This article is published with open access at Springerlink.com

\begin{abstract}
Climate fluctuations in the North Atlantic Ocean have wide-spread implications for Europe, Africa, and the Americas. This study assesses the relative contribution of the long-term trend and variability of North Atlantic warming using EOF analysis of deep-ocean and near-surface observations. Our analysis demonstrates that the recent warming over the North Atlantic is linked to both long-term (including anthropogenic and natural) climate change and multidecadal variability (MDV, $\sim 50$ 80 years). Our results suggest a general warming trend of $0.031 \pm 0.006^{\circ} \mathrm{C} /$ decade in the upper $2,000 \mathrm{~m}$ North Atlantic over the last 80 years of the twentieth century, although during this time there are periods in which shortterm trends were strongly amplified by MDV. For example, MDV accounts for $\sim 60 \%$ of North Atlantic warming since 1970. The single-sign basin-scale pattern of MDV with prolonged periods of warming (cooling) in the upper ocean layer and opposite tendency in the lower layer is evident from observations. This pattern is associated with a slowdown (enhancement) of the North Atlantic thermohaline overturning circulation during negative (positive) MDV phases. In contrast, the long-term trend exhibits warming in tropical and mid-latitude North Atlantic and a pattern of
\end{abstract}

I. V. Polyakov $(\varangle) \cdot$ V. A. Alexeev $\cdot$ X. Zhang

International Arctic Research Center, University of Alaska

Fairbanks, 930 Koyukuk Drive, Fairbanks, AK 99775, USA

e-mail: igor@iarc.uaf.edu

\section{U. S. Bhatt}

Geophysical Institute, University of Alaska Fairbanks, 930 Koyukuk Drive, Fairbanks, AK 99775, USA

\section{E. I. Polyakova}

Department of Geological and Environmental Studies, Stanford University, Stanford, CA 94305, USA cooling in regions associated with major northward heat transports, consistent with a slowdown of the North Atlantic circulation as evident from observations and confirmed by selected modeling results. This localized cooling has been masked in recent decades by warming during the positive phase of MDV. Finally, since the North Atlantic Ocean plays a crucial role in establishing and regulating the global thermohaline circulation, the multidecadal fluctuations discussed here should be considered when assessing long-term climate change and variability, both in the North Atlantic and at global scales.

Keywords North Atlantic · Multidecadal variability . Climate change

\section{Introduction}

Substantial North Atlantic climate changes have occurred over recent decades (e.g. Levitus et al. 2000). Despite the fact that these changes have contributed to observed warming of the Northern Hemisphere, including rapid warming over Europe and high-latitude regions, and to changes in terrestrial and marine ecosystems, an understanding of the governing mechanisms and their attribution either to human-induced (anthropogenic) climate change or to natural variability has not been well established (IPCC 2007). This uncertainty has sparked debate about the relative roles of multidecadal variability (MDV) versus anthropogenic forcing in the observed warming in the tropical Atlantic, which is closely related to the Atlantic hurricane activity (Mann and Emanuel 2006). Much of this debate centers around how to define the strength of the multidecadal variations which occur on a timescale of 50-80 years and have large amplitude 
variations in the North Atlantic (Schlesinger and Ramankutty 1994).

These low-frequency fluctuations are evident in various instrumental and proxy records from the Northern Hemisphere (see Delworth and Mann 2000 for references therein) but much is not understood about MDV. A study of the proxy and long-term instrumental records by Stocker and Mysak (1992) emphasized that these low frequency variations, though global in extent, are most pronounced in the Atlantic Ocean. Folland et al. (1986) reached the same conclusion from an analysis of global sea surface temperatures (SST). A time series of area-averaged North Atlantic SST with the local trend removed defines the so called Atlantic multidecadal oscillation (AMO, Enfield et al. (2001)). There are, however arguments that the observed SST changes are not consistent with the linear North Atlantic trend used to define the AMO. A revised AMO index was proposed in which the global SST trend was removed instead. Defined this way, the revised AMO accounts for only $0-0.1^{\circ} \mathrm{C}$ of the recent North Atlantic SST anomaly, several times less than what would be accounted for by the "standard" AMO (Trenberth and Shea 2006). Parker et al. (2007) applied empirical orthogonal function (EOF) analysis to a global SST dataset and argued that the AMO appears as the third EOF with a weak trend similar to that from Trenberth and Shea (2006).

The relatively short instrumental records of the AMO are augmented with paleoclimate data to provide evidence of a multidecadal signal over several centuries (e.g. Gray et al. 2004; Divine and Dick 2006; Fritzsche et al. 2005). Part of the difficulty in identifying the low-frequency fluctuations and understanding mechanisms behind the MDV is due to it's evolving spectrum, and the changing relationship with between SAT/SST (SAT, surface air temperature) and the large-scale atmospheric forcing like the North Atlantic oscillation (NAO, defined as the northsouth-oriented dipole in sea-level pressure (SLP) over the Atlantic) (Polyakova et al. 2006). For example, in contrast to the warming of the 1990s, the 1930s warm period in the Arctic did not coincide with a strongly positive phase of the NAO (Overland et al. 2004), as would be expected based on the NAO paradigm of greater heat transport into the Arctic when the NAO is positive. This led to the conjecture that the mechanism of the warming of the 1930s was associated with local air-sea-ice interactions (Bengtsson et al. 2004) and the recent warming was due to a different mechanism. Atmospheric heat-transport mechanisms which are important for high-latitude heat budget but at the same time unrelated to the positive surface albedo feedback were described in (Alexeev 2003; Alexeev et al. 2005; Langen and Alexeev 2007). An extensive analysis of Arctic and North Atlantic atmosphere, ocean, and ice observations demonstrates that there are many similarities between these two warm periods, suggesting that both periods are associated with related mechanisms (e.g. Polyakov et al. 2008).

Nevertheless, numerous studies (e.g. Bjerkness 1964; Deser and Blackmon 1993; Kushnir 1994; Dickson et al. 1996, 2002; Timmermann et al. 1998; Curry et al. 1998, 2003; Häkkinen 1999; Curry and McCartney 2001; Visbeck et al. 2002; Peterson et al. 2006) point to the important role of the NAO in climate variability in the North Atlantic Ocean, making it critical to understand why the NAO paradigm does not always operate.

While the physical mechanisms for generating MDV may differ from model to model (e.g. Latif 1998), there is a consensus that long-term changes in the thermohaline (e.g. density-driven) circulation (THC) play a crucial role in establishing spatial and temporal SST patterns (e.g. Delworth et al. 1993; Timmermann et al. 1998; Häkkinen 1999; Delworth and Greatbatch 2000; Eden and Jung 2001; Barnett et al. 2005; Knight et al. 2005; Hawkins and Sutton 2007; Zhang et al. 2007). The North Atlantic THC is associated with the meridional overturning circulation (MOC), a northward flow of warm, low-density surface waters balanced by a commensurate southward flow of cold, high-density waters at depth. There is compelling evidence to support the notion that phases of MDV expressed by the AMO and the strength of the MOC are interrelated. For example, Parker et al. (2007) analyzed modeling results and demonstrated that a weak (strong) MOC is associated with a cooler (warmer) North Atlantic. Parker et al. also demonstrated that models encounter substantial problems in simulating MDV of the NAO.

Thus, it is imperative to understand long-term fluctuations in the North Atlantic by linking changes at the ocean surface and in the ocean interior with possible changes in sea surface height, strength of the oceanic circulation and air-ocean interactions. This study assesses the relative contribution of the long-term trend and variability to warming in the North Atlantic by evaluating these processes without any a priori assumptions about their shape. In this paper, we use the term "long-term climate change" without distinguishing between anthropogenic climate change and additional (longer than multidecadal) low-frequency natural variations that are not resolved by the observational records in accordance with the IPCC (2007).

\section{Data and methods}

The analysis area for this study is the North Atlantic Ocean between $0-80 \mathrm{~N}$ and $60 \mathrm{~W}-20 \mathrm{E}$. The observational oceanographic dataset combines the World Ocean Database 2005 (Boyer et al. 2006) and data from the World Ocean Circulation Experiment (WOCE) from 1990 to 1997 (WOCE Global Data Resource DVD, Version 3.0). We 
avoid observations before 1920 because of substantial spatial and temporal gaps in data coverage, particularly in the deep ocean (for details of data coverage we refer to Fig. 1, see also Fig. 1 from Polyakov et al. 2005). Numerous tests were performed to evaluate the possible impacts on our results of gaps in data and lack of data in the early part of the record. These tests demonstrate the robustness of our estimates (see Appendix for details). The seasonal cycle was removed from the data. Finally, annual zonal mean water temperature anomalies were constructed. Zonal averaging within $2^{\circ}$ latitudinal belts provides an important large-scale perspective on the changes in the North Atlantic Ocean; however, because of this averaging, many of the regional details are missing. Various methods of spatial averaging within the latitudinal belts were tested, and the results of these test experiments are presented in the Appendix. Empirical orthogonal function (EOF) analysis was applied to the correlation matrix to evaluate the modal structure of zonal mean water temperature. EOF analysis provides a useful tool for identifying key patterns of variability from large quantities of data. It is most useful when the identified modes of variability can be related to distinct physical processes, which we argue is the case in our analysis. The data were linearly interpolated onto a vertical grid with constant $50 \mathrm{~m}$ increments to assure that each volume of water was treated equally in the estimation of the EOFs. For the EOF analysis anomalies were normalized by their standard deviations in order to highlight changes in the deeper ocean. The associated time series (principal component, or PC) for the EOFs were re-scaled by multiplying by standard deviations to have the same units as the original variables. The leading EOF captures the long-term trend, leaving the higher order EOF harmonics de-trended.

The major emphasis of this study comprises an analysis of observations but is augmented with a model analysis that focuses on the climate dynamics of the long-term trend. For this purpose, we used twentieth century (1900-1999, 20C3M) model runs from four fully coupled global climate models: BCCR-BCM2.0, CCSM3, GFDL-CM2.0, and

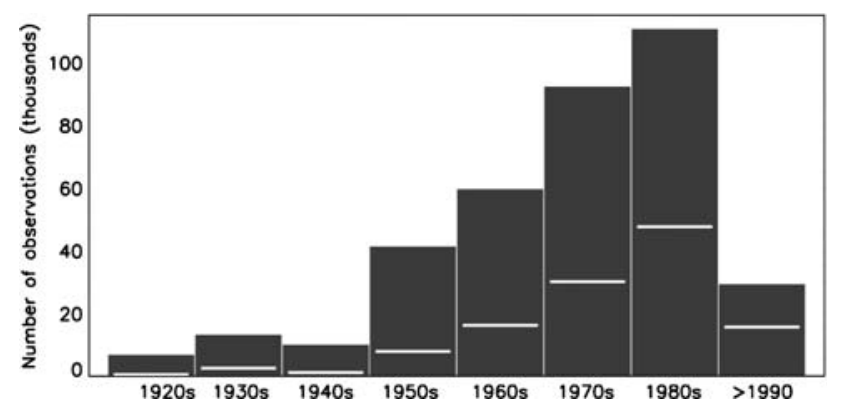

Fig. 1 Number of observational stations used for analysis. White horizontal lines within the grey bars show the number of observations available for analysis of the deeper Atlantic Ocean $(>1,000 \mathrm{~m})$
UKMO-HadCM3. These models were among a suite used for the latest Intergovernmental Panel on Climate Change (IPCC) Fourth Assessment Report (2007). These four models were selected because their simulation of northsouth long-term contrast of the North Atlantic SST is in reasonably good agreement with observations. Detailed information about the models and their simulation design can be found at http://www-pcmdi.llnl.gov/ipcc/model_ documentation/ipcc_model_documentation.php and the embedded modeling centers' website links. The climate of the twentieth century is forced with observed emissions which includes greenhouse gas concentrations and, in some cases, aerosol and variable solar forcing. In order to avoid potential impacts from model spin-up, all the models were initialized at various antecedent times early in the mid- or late-nineteenth century. When processing model data, we followed the analysis procedure used for the observational data as closely as possible: model data were averaged within the same zonal belts and interpolated vertically onto the vertical grid used for analysis of the observational data. This approach facilitates the comparison of observed and simulated EOFs of zonal mean temperatures.

The net radiative forcing used to interpret our results was obtained from http://data.giss.nasa.gov/modelforce/ by computing a cumulative time series with the mean removed based on data prior 1900 (in the text, we will refer to this parameter as "radiative forcing"). Maximenko (IPRC) and Niiler (SIO) provided ocean dynamic topography data. ICOADS Sensible Heat Flux data (ICOADS 2-degree Enhanced Release 2.3) were provided by the NOAA/OAR/ ESRL PSD, Boulder, Colorado, USA from http://www.cdc. noaa.gov/. SLP $(5 \times$ resolution, $15-90 \mathrm{~N})$ was provided by NCAR based on the methods of Trenberth and Paolino (1980) from www.cgd.ucar.edu/cas/guide/Data/trenpaol. html. SST data $(5 \times 5$ Kaplan extended SST v.2) were obtained from NCAR at www.cgd.ucar.edu/cas/guide/ Data/kaplan_sst.html (Kaplan et al. 1998). Regression analysis of SLP, SST, and heat fluxes on the PCs was performed in order to illustrate the spatiotemporal behavior of these parameters.

\section{Separating leading modes of North Atlantic variability}

The two leading modes of zonal average water temperature variability, based on EOF analysis of observational data are shown in Fig. 2a, c. A 9-year running mean has been applied to the data prior to the EOF analysis; filtering has a rather minor effect on the leading EOFs (i.e. pattern correlations were $R=0.89 / 0.77$ between EOF1/EOF2 of smoothed and unsmoothed data). The first two EOFs explain 28.1 and $20.2 \%$ of variability, respectively and are significantly 

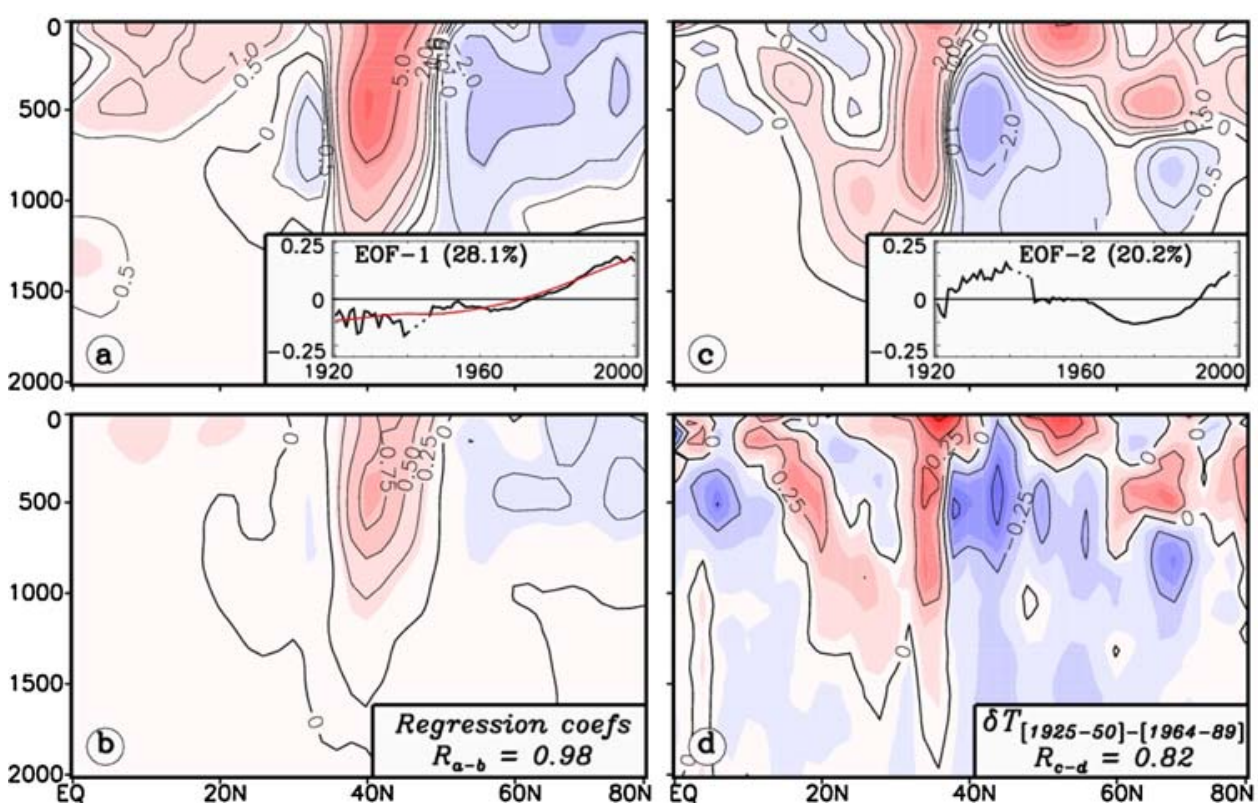

Fig. 2 Patterns of zonal average North Atlantic Ocean temperature variability associated with the nonlinear trend (left column) and multidecadal variability (right column). a EOF-1 (insert shows PC1, ${ }^{\circ} \mathrm{C}$, black, and radiative forcing, red); for comparison, $\mathbf{b}$ regressions of zonal average water temperature on the radiative forcing time series $\left(10^{-1}{ }^{\circ} \mathrm{C} / \mathrm{ppm}\right)$. c EOF-2 (insert shows $\mathrm{PC} 2,{ }^{\circ} \mathrm{C}$ ); for comparison, $\mathbf{d}$ zonal average water temperature difference between

separated from each other (North et al. 1982, see Appendix for discussion of sensitivity of the EOF analysis to various errors, including incomplete spatial and temporal coverage, outliers and gaps in the "raw" temperature data, random noise in observational data, and separation of modes of variability). The largest variability exists at depths shallower than $1,000 \mathrm{~m}$. The associated time series (principal component, or PC) for EOF1 (PC1) is characterized by an upward trend that is positively correlated $(R=0.95)$ with anthropogenic radiative forcing (shown in red in Fig. 2a inset and 3). PC2 is characterized by multidecadal variations and compares favourably with the AMO index (with AMO/PC2 correlated at $R=0.59$ ). As with the AMO, PC2 displays positive values in recent decades and in the 1930-1940s, and negative values in the 1960-1970s. This suggests that the long-term trend and low-frequency multi-decadal variations in the North Atlantic Ocean temperature are associated with two distinctly different patterns of variability.

Modal decompositions of climate must be viewed with caution, so additional evidence is provided to establish a solid physical basis for these EOF-based patterns. In Fig. 2, panel B presents the regressions of zonal average ocean temperatures on the radiative forcing time series (which, due to its high correlation with the PC1 at zero lag, is used as a proxy for the long-term trend), and panel D shows the zonal mean water temperature difference between the positive (warm) and negative (cold) phases of MDV positive and negative phases [(1925-1950)-(1964-1989)] of multidecadal variability $\left({ }^{\circ} \mathrm{C}\right.$ ) (detrending of the data is applied using nonlinear trends defined by the radiative forcing time series; weak three-point four-passes smoothing based on the Laplacian operator is applied). $R$ indicates pattern correlations between the corresponding panels

defined by PC2 (note that in this analysis temperatures were de-trended using the radiative forcing time series). The similarities between these two panels and their corresponding EOFs are striking and are confirmed by a high pattern correlation between panels $\mathrm{A}$ and $\mathrm{B}\left(R_{a}-b=0.98\right)$ and a somewhat weaker, but still significant correlation between panels $\mathrm{C}$ and $\mathrm{D}\left(R_{c}-d=0.82\right)$. Note that agreement between panels $\mathrm{C}$ and $\mathrm{D}$ supports the validity of choosing 1925-1950 (1964-1989) to define the warm (cold) or positive (negative) phase of MDV. To substantiate our results from yet another angle, EOF analysis was applied to the heat content of the upper $0-300 \mathrm{~m}$ in the North Atlantic. EOF 1 and 2 of heat content compare favorably with SST regression patterns shown in Fig. 5. Further support for the EOF-based decomposition of the available data for the long-term trend and MDV is provided by comparing the PCs of zonal mean water temperature and upper 0-300 m heat content (i.e. vertical vs. horizontal distributions, Fig. 4). This comparison shows reasonably high similarity between these PC1s $(R=0.75)$ and PC2s $(R=0.50)$. This also gives us confidence that the normalization of water temperature anomalies prior EOF analysis does not suppress the surface signal by overemphasizing subsurface temperature variability which presumably has larger observational errors than the more accurate surface values. Appendix provides further discussion of EOF-based separation of modes of variability. Thus, we agrue that the 
Fig. 3 Time evolution of key parameters of the North Atlantic climate system. a PC1 of zonal average water temperature $\left({ }^{\circ} \mathrm{C}\right.$, black) and radiative forcing (red). b PC2 of zonal average water temperature $\left({ }^{\circ} \mathrm{C}\right.$, black $)$ and a proxy for 6-year running mean wind vorticity anomalies for the area marked by a box in Fig. 5, computed from SLP as a finite-difference numerator of the Laplacian function $(\mathrm{hPa}$, red, note the reverse vertical axis). c Six-year running mean SST anomalies $\left({ }^{\circ} \mathrm{C}\right.$, black $)$ and composite time series of the upper $300 \mathrm{~m}$ water temperature anomalies $\left({ }^{\circ} \mathrm{C}\right.$, red , adapted from (Polyakov et al. 2005)). d Six-year running mean composite time series of the upper $300 \mathrm{~m}$ water salinity anomalies [psu, adapted from (Polyakov et al. 2005)]. Dashed segments identify data gaps

Fig. 4 Comparison of PC1 (top) and $\mathrm{PC} 2$ (bottom) derived from $\mathrm{EOF}$ analysis of zonal average water temperature $\left({ }^{\circ} \mathrm{C}\right.$, black) and 0-300 $\mathrm{m}$ upper ocean water temperature $\left({ }^{\circ} \mathrm{C}\right.$, red). No smoothing is used in this analysis. Dashed segments identify data gaps. $R$ show correlations between the corresponding PCs
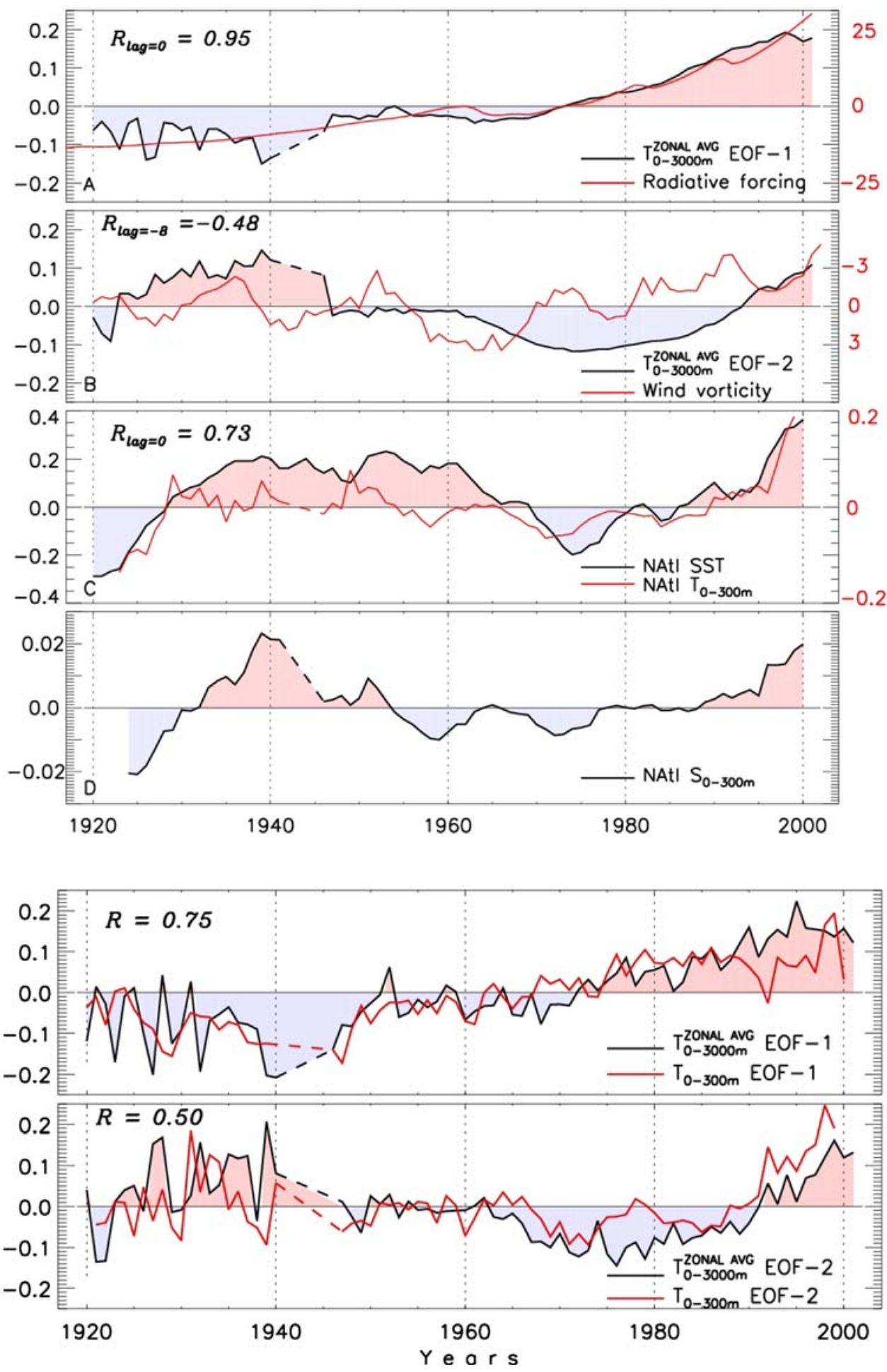

two leading EOFs of the North Atlantic zonal mean temperatures may be associated with the nonlinear trend and MDV, respectively.

Comparing the rates of warming from 1920 to 2004 shown by $\mathrm{PC} 1$ and $\mathrm{PC} 2$, we find that an average warming rate of $0.031 \pm 0.006^{\circ} \mathrm{C} /$ decade can be attributed to the nonlinear trend. This trend is expectedly weaker compared with the global linear SST trend of $0.071 \pm 0.016^{\circ} \mathrm{C} / \mathrm{dec}$ ade calculated over 1901-2006 (Parker et al. 2007) since our estimates include deeper (down to 3,000 m) oceanic layers with substantially weaker variations. MDV had little net effect on computed trends over 1920-2004: this is to be expected because the positive and negative phases nearly cancel one another out (Fig. 3b, Table 1). We can, 
Table 1 Trends $\left({ }^{\circ} \mathrm{C} /\right.$ decade) of principal components (PCs) of the EOF analysis of zonal average North Atlantic water temperature

\begin{tabular}{lllll}
\hline \multicolumn{1}{l}{ Years } \\
\hline & $1920-2002$ & $1940-2002$ & $1950-2002$ & $1970-2002$ \\
\hline PC1 & $0.031 \pm 0.006$ & $0.045 \pm 0.007$ & $0.043 \pm 0.011$ & $0.060 \pm 0.036$ \\
PC2 & $0.006 \pm 0.007$ & $0.008 \pm 0.011$ & $0.014 \pm 0.013$ & $0.081 \pm 0.019$
\end{tabular}

however, identify periods in the 85-year record when the relative contribution of MDV to the trend was greatly enhanced. Since 1970, for example, MDV (PC2) accounts for almost $60 \%$ of the combined $\mathrm{PC} 1+\mathrm{PC} 2$ warming tendency. Thus, we argue that the recent observed North Atlantic warming may be linked to both MDV and longterm climate trend.

Spatial patterns of SST anomalies corresponding to the two leading modes of variability (constructed by regressing SST on PC1/PC2) provide further insight into a complex interplay between MDV and long-term climate change in the North Atlantic (Fig. 5). The SST pattern associated with the long-term trend displays anomalously cold surface water located in the regions of major North Atlantic surface heat transports, including the Gulf Stream-North Atlantic Current system and their poleward continuation, the Norwegian Current. This is consistent with the EOF1 pattern (Fig. 2a), where high-latitude $(>50 \mathrm{~N})$ cooling in recent decades is evident to depths of $1,000 \mathrm{~m}$ and contrasts with tropical and subtropical warming (Fig. 2a). Note that a similar spatial pattern was obtained for century-long North Atlantic SST linear trends (Cane et al. 1997) and for upper $700 \mathrm{~m}$ North Atlantic heat content change from 1955 to 2003 as defined by EOF analysis (IPCC 2007, Figure 5.2 adapted from Levitus et al. 2005). A somewhat different pattern of the long-term climate trend was obtained by Parker et al. (2007) based on EOF analysis of global SSTs and nighttime marine air temperatures, where there is no widespread cooling in the northern North Atlantic. Parker et al. (2007) found, however, weaker trends in the northern North Atlantic with negative trends in the central Labrador Sea. These differences may be associated with spatial filtering of the original data prior to the EOF analysis. Spatiotemporal features of multidecadal fluctuations are presented in the Sect. 4.

\section{Features of North Atlantic multidecadal variability}

The striking resemblance between MDV of the North Atlantic, whether expressed by PC2, SST, or upper $300 \mathrm{~m}$ water temperature and salinity anomalies (Fig. 3), supports the hypothesis that "universal" mechanisms govern North Atlantic large-scale low-frequency variations. Numerous studies point to the importance of the NAO in forcing low- frequency variations in the North Atlantic Ocean. Our analysis suggests that some observed features of North Atlantic MDV may be associated with the NAO. For example, the maximum statistically significant correlation of $R=0.48$ between the NAO and PC2 is found with an 11-year lag, which is consistent with earlier findings of a delayed oceanic response to atmospheric forcing (e.g. Eden and Willebrand 2001). However, the SLP anomalies obtained by regressing lagged SLP on PC2 (Fig. 5) agree better with the East Atlantic pattern (not shown), one of the leading EOF modes of the SLP (Barnston and Livezey 1987). Regression analysis of SST on PC2 reveals a singlesign basin-scale anomaly pattern characteristic of multidecadal fluctuations in the North Atlantic SST (Fig. 5) consistent with earlier findings (e.g. Bjerkness 1964; Kushnir 1994; Delworth and Greatbatch 2000; and Eden and Willebrand 2001; see also Polyakov et al. (2005) and Visbeck et al. (2002) for further discussion and references therein). Multidecadal fluctuations in the zonal mean water temperature as expressed by the EOF2 (Fig. 2) are dominated by warming (cooling) in the upper $300 \mathrm{~m}$ layer and cooling (warming) in the 1,000-3,000 m layer during the positive (negative) MDV phase. Note that the deeper ocean displays anomalies that are approximately $40 \%$ of the upper ocean anomalies. This is generally consistent with changes in SST (Fig. 5) and supported by earlier studies (Polyakov et al. 2005; Zhang 2007). For example, using observational data, Polyakov et al. (2005) demonstrated that temperature and salinity from the $0-300$ to 1,000 $3,000 \mathrm{~m}$ layers vary in opposition: prolonged periods of cooling and freshening (warming and salinification) in one layer are generally associated with opposite tendencies in the other layer. This pattern may be associated with a change in the strength of MOC.

Epochal analysis (cold-warm MDV phase) of zonal mean density shows stronger meridional density gradients between the high-latitude North Atlantic and lower-latitude regions $(\sim 52-65 \mathrm{~N})$ associated with negative, cold phases of MDV (Fig. 6) which is also consistent with a strong northeastward density-driven flow. The opposite is true for the warm, positive, MDV phase. Note that the mean density increases with latitude generating a sea level height decreasing northward. A slowdown of the subpolar gyre was evident in the late 1990s-early 2000s during the positive or warm MDV phase (Häkkinen and Rhines 2004). The density gradients in the tropics $(<30 \mathrm{~N})$ are also suppressed during the warm phase of MDV, consistent with a slowing of the density-driven component of the equatorial current system. This result is in agreement with Bryden et al.'s (2005) comparison of transatlantic oceanographic transects carried out in 1957, 1981, 1992, 1998 and 2004 along $\sim 25 \mathrm{~N}$. Bryden et al. suggested that the Atlantic MOC has slowed by $\sim 30 \%$ since 1957 . However, Latif 
Fig. 5 Regression coefficients of (top) SST $\left({ }^{\circ} \mathrm{C} /{ }^{\circ} \mathrm{C}\right)$, (middle) sensible heat flux $\left(\mathrm{SH}, \mathrm{cm} /{ }^{\circ} \mathrm{C}\right.$, positive is up), and (bottom) $\mathrm{SLP}\left(\mathrm{hPa} /{ }^{\circ} \mathrm{C}\right)$ associated with long-term climate change (left column) and multidecadal variability (right column). The maps are constructed by regressing the corresponding parameter on $\mathrm{PC} 1$ and $\mathrm{PC} 2$. Note that the multidecadal pattern of the SLP is lagged by eight years relative to PC2 (SLP leads) reflecting the delayed oceanic response to atmospheric forcing (Fig. 3). Areas of cooler water are associated with the major North Atlantic Current system (top left panel) and this pattern is consistent with the hypothesis that the circulation is slowing due to climate change; this effect has been masked in recent decades by the strong warming associated with the positive (warm) phase of multidecadal variability (top right panel). Areas with statistical confidence less than $90 \%$ are stippled
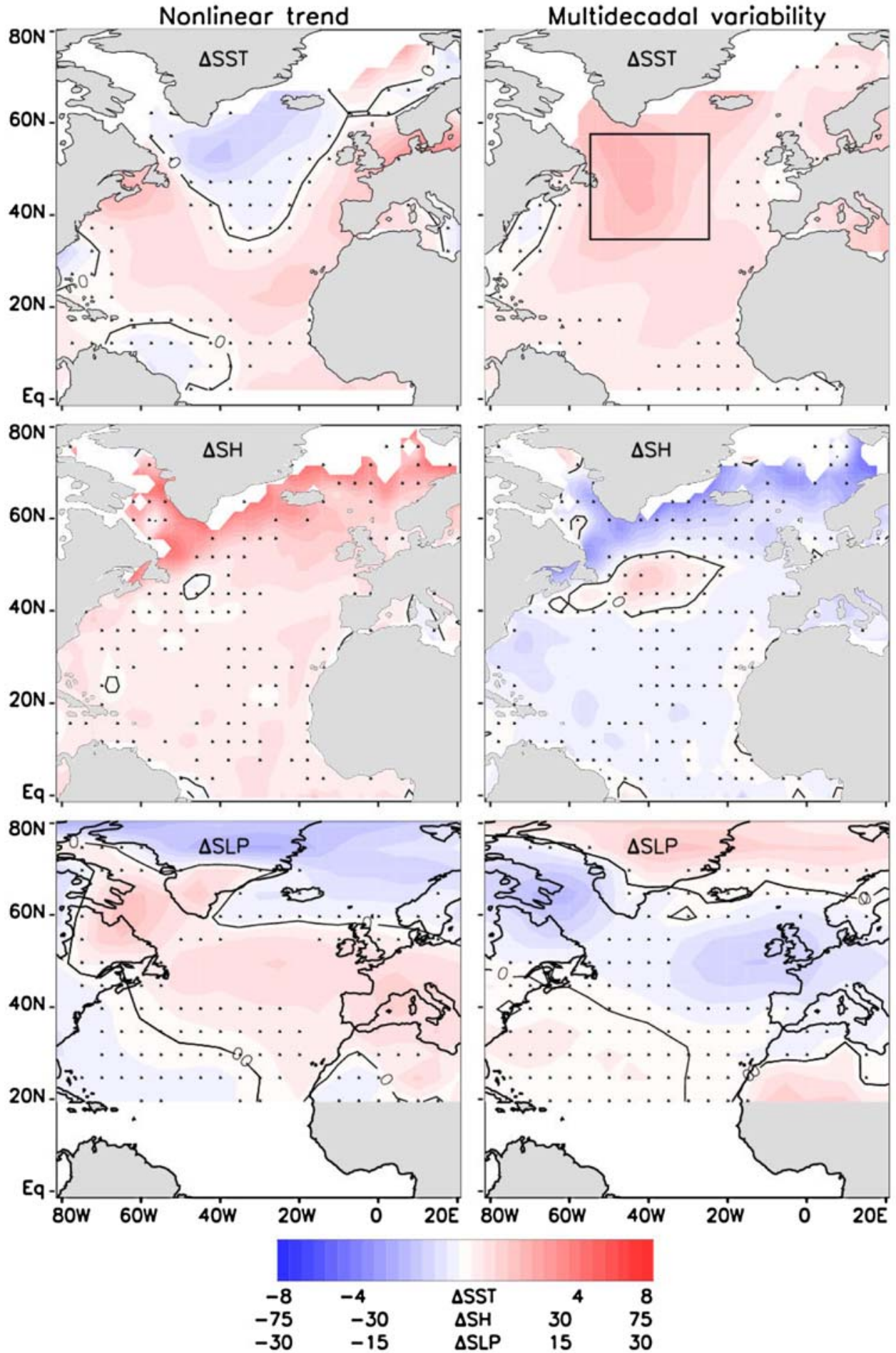

et al. (2006) analyzed observational data and modeling results to find no evidence of sustained THC weakening in the last few decades suggesting that changes of THC during the last century resulted from natural multidecadal climate variability. Moreover, Cunningham et al. (2007) noted that the snapshot observations used by Bryden et al. (2005) are aliased by large intra-annual variations. Direct observations of the Deep Western Boundary Current indicate no basin-wide slowdown of MOC in the recent decade [Schott et al. 2006]. Our analysis shows that reduced basinwide $(0-80 \mathrm{~N})$ meridional density or pressure gradients during a cold MDV phase imply that the MOC (including Gulf Stream and southern part of the North Atlantic Current) is weaker. This is consistent with modeling results by 
Hawkins and Sutton (2007) and with the negative subsurface density anomaly between 40 and $60 \mathrm{~N}$ (Fig. 6). In addition, it may be a manifestation of weaker convection in the Labrador Sea observed in 1965-1985 (Curry et al. 1998).

To further examine and quantify the contribution of density change to ocean circulation variability, we estimate changes of potential energy anomaly and sea surface height due to long-term changes in North Atlantic temperature and salinity. The potential energy anomaly, $\chi$, as a measure of dynamic sea surface height ( $\mathrm{SSH}$ ), provides a quantitative estimate of the intensity of horizontal gyres by illustrating geostrophic velocities and mass transports (Curry and McCartney 2001). $\chi$ may be defined as the vertical integral of the specific volume anomaly $\delta$ multiplied by pressure $p$ and divided by the gravity constant $g$

$\chi=\frac{1}{g} \int_{p}^{0} p \delta d p$

Figure 7 shows the difference $(\delta \chi)$ of the zonal average $0-3,000 \mathrm{~m} \chi$ between the cold and warm phases of MDV (note that $\delta \chi$ is well correlated, $R=0.79$, to SSH changes). This comparison suggests that the change in the density structure over prolonged periods of cooling (warming) has acted to enhance (offset) the sea level slopes in the subtropical $(<30 \mathrm{~N})$ and subpolar $(>50 \mathrm{~N})$ areas and to suppress (enhance) sea level slope within the $30-50 \mathrm{~N}$ zonal belt consistent with our analysis of density gradients (Fig. 6). Consequently, a steeper sea level slope causes a water particle to move faster down the slope while also deflecting to the right due to the Earth's rotation, resulting in a stronger gyre circulation in the upper ocean. An estimate of the temporal change in the density-driven water transport (defined as the basin-wide, $0-80 \mathrm{~N}$, meridional difference of $\delta \chi$ divided by the appropriate Coriolis parameter, Curry and McCartney 2001) yields about $2 \mathrm{~Sv}$ $\left(1 \mathrm{~Sv}=10^{6} \mathrm{~m}^{3} / \mathrm{s}\right)$ of decreased flow in the cold phase as compared to the warm phase of MDV, or about $10 \%$ of the estimated change of the density-driven transport in the Gulf Stream-North Atlantic Current system from the 1970s to the 1990s (Curry and McCartney 2001). This estimate represents the direct contribution of the density-driven surface current only and does not account for the winddriven component of the flow which was probably amplified due to enhanced westerlies (Shabbar et al. 2001; Zhang et al. 2004).

The response of large-scale oceanic circulation to atmospheric forcing is further evaluated using the theory of Marshall et al. (2001a, b). They showed that a circulation anomaly called the 'intergyre' gyre (its approximate position is shown by the box in Fig. 5) is driven by meridional
Fig. 6 Zonal average water density $\left(\mathrm{kg} / \mathrm{m}^{3}\right)$ difference between cold and warm phases of multidecadal variability. (Top panel) Potential density and (bottom panel) potential density averaged over the water column from the surface to gradually increasing depth (equivalent to pressure)

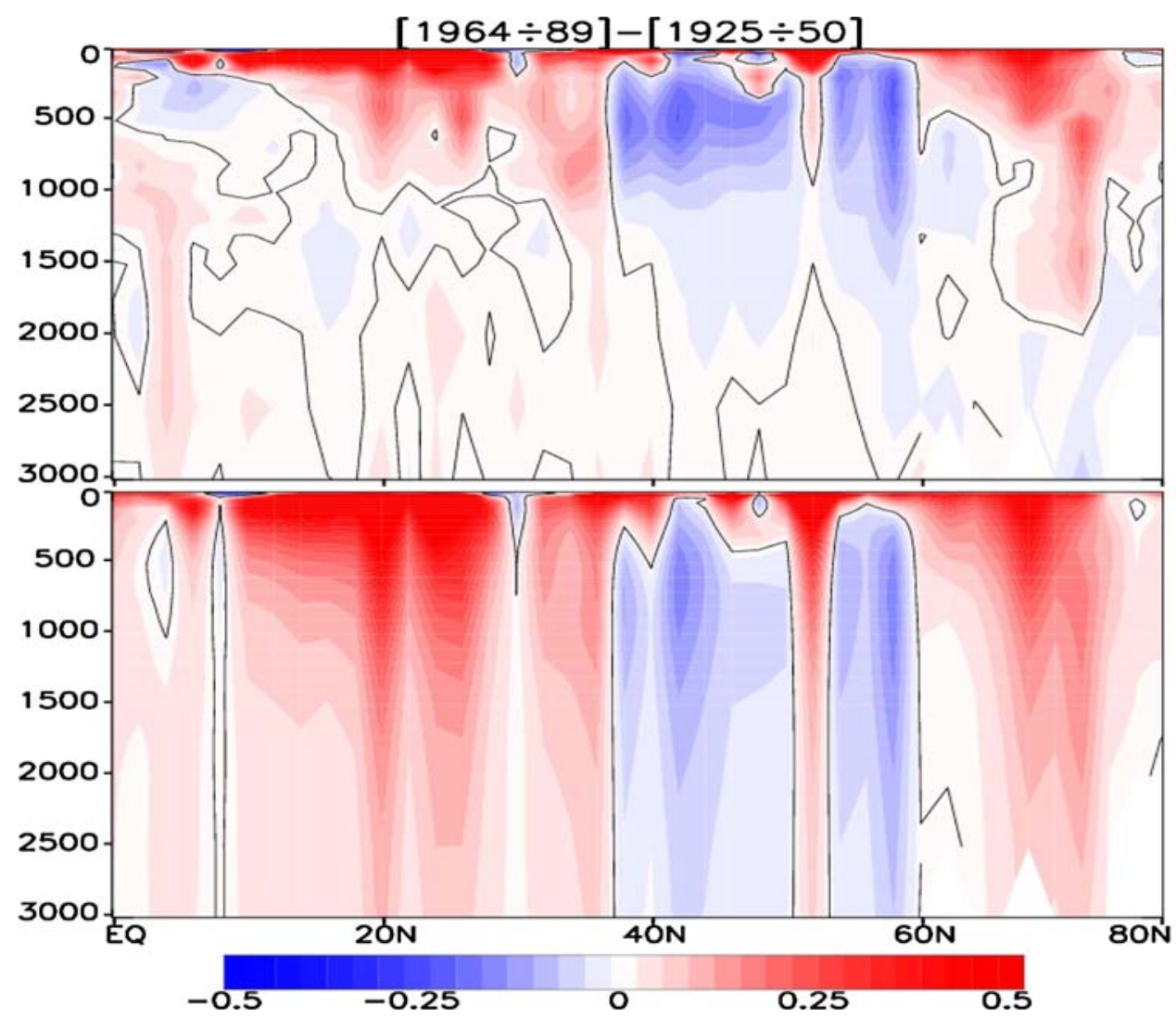




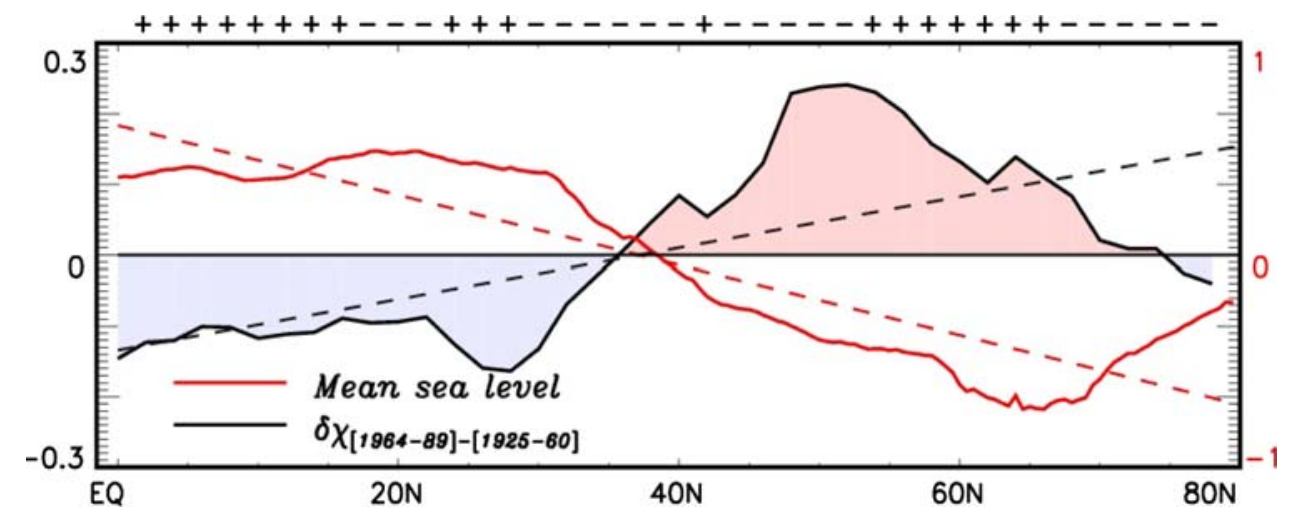

Fig. 7 Zonal average time-mean (1992-2002) ocean dynamic topography $(r e d, \mathrm{~m})$ and difference of the potential energy anomaly $\delta \chi\left(\mathrm{MJ} / \mathrm{m}^{2}\right)$ between phases of multidecadal variability. These changes are consistent with changes of dynamic sea surface height. The same sign of local slopes of these two curves (marked by "+" symbols at the top of the panel) signifies that the zonal mean surface

shifts in the zero wind curl which is climatologically located between the subpolar and subtropical gyres. According to Marshall et al. (2001a, b), the oscillatory behavior of the intergyre gyre is governed by north-south heat transports by anomalous currents, balanced by damping of the SST anomalies via air-sea interactions. Our analysis provides further evidence supporting the important role played by the intergyre gyre in establishing and regulating multidecadal temperature variations of the North Atlantic (Fig. 5). For example, MDV of the zonal average temperatures expressed by PC2 and wind curl anomalies computed over the intergyre gyre region (Fig. 3) are negatively correlated $(R=-0.44)$ at an 8 -year lag. This is consistent with a delayed oceanic response to the atmospheric forcing found in modeling (Eden and Willebrand 2001) and theoretical (Marshall et al. 2001a, b) studies. During prolonged phases of high (low) wind vorticity there is anomalous upwelling (downwelling) centered at $\sim 45 \mathrm{~N}$ concurrent with lower (higher) SSTs and decreased (increased) surface heat fluxes out of the ocean (Fig. 5). This pattern is consistent with the ocean response to the NAO simulated by GCMs (e.g. Eden and Willebrand 2001; Vellinga and Wu 2004) and is confirmed by the statistically significant minimum in the regression pattern of SST on wind vorticity index lagged by 8 years (not shown). We find that the change of density structure during cold (warm) phases of MDV suppresses (enhances) the intergyre gyre as seen from increased (decreased) SSH slopes when the circulation is enhanced (suppressed) (Fig. 7). An important implication for Arctic-North Atlantic interactions is that the intergyre dynamics introduces much shorter timescales than those imposed by the thermohaline circulation (planetary-scale conveyor) (Marshall et al. 2001a, b). density-driven circulation is amplified by the anomalous density structure during the negative (cold) phase of multidecadal fluctuations. $0-80 \mathrm{~N}$ slopes are shown by dashed lines. Note that time interval used for averaging of $\delta \chi$ over the positive MDV phase is somewhat longer than previously used (e.g. Fig. 2) allowing more robust estimates of $\delta \chi$

\section{Long-term trend and multidecadal variability from four IPCC models}

Analysis of model data is necessary for developing an understanding of causality of climate processes since observations result from all processes and feedbacks in nature while models represent only a part of the fullycoupled system and often not all needed variables are observed. In this section, model data are used to gain insight about governing forces driving observed long-term changes hypothesized from the analysis of Sects. 3-4. Specifically, we use modeling results to gain a better understanding of the observed long-term cooling of the northern North Atlantic as expressed by EOF1. Multimodel ensembles have been used by Kravtsov and Spannagle (2008) to estimate the contribution of radiative forcing to twentieth century trends. The readily available multi-model IPCC twentieth century scenario data archives are the ideal tool for such an exercise. We focus on four general circulation models that participated in the recent IPCC Report (2007) and repeat the same analysis on model data as was done for the observations in the previous sections. These four models were selected because their simulation of north (cool)-south (warm) long-term contrast of the North Atlantic SST is in reasonably good agreement with observations. The model results are compared with the observed analysis to evaluate the models as well as explore possible mechanisms. Note that the objectives of this analysis are somewhat restricted - we do not attempt to explore physical mechanisms in-depth which would require performing a suite of model sensitivity simulations but rather use available simulations to determine what types of responses are possible in the models. 
Fig. 8 Patterns of zonal average North Atlantic Ocean temperature variability associated with the nonlinear trend (left column) and multidecadal variability (right column) simulated by four general circulation models. Left panels show EOF1 (insert shows $\mathrm{PC} 1,{ }^{\circ} \mathrm{C}$, black, and radiative forcing, red). Right panels show EOF2 (insert shows $\mathrm{PC} 2,{ }^{\circ} \mathrm{C}$ )
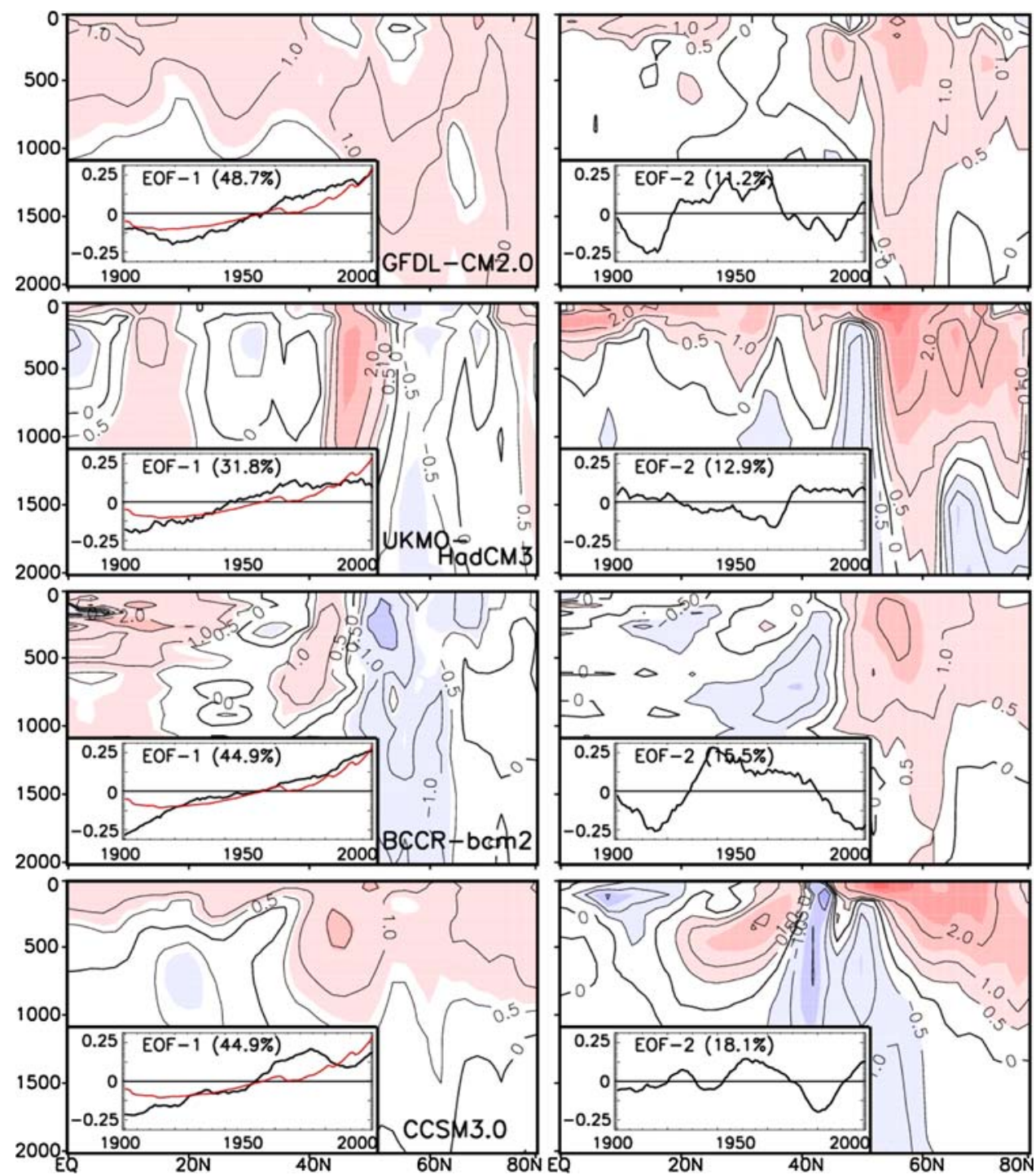

All of the models are successful in simulating the warming trend of zonal mean water temperature expressed by their corresponding $\mathrm{PC} 1 \mathrm{~s}$, however, they show rather different levels of skill in reproducing the spatial structure of ocean temperature as shown by pattern correlations $R$ (compare observation-based EOF1/PC1, Fig. 2, and modelbased EOF1s/PC1s, Fig. 8). The GFDL-CM2.0 $(R=$ $-0.13)$ and CCSM3.0 $(R=-0.09)$ simulations show a single-sign basin-wide upper ocean warming, which resembles the response of a two-layer liquid to surface radiative forcing. The HadCM3 $(R=0.27)$ and, especially, the BCCR-BCM2.0 $(R=0.53)$ simulations capture the major structure of the observed ocean temperature with a positive temperature anomaly at the intergyre-gyre location at $\sim 45 \mathrm{~N}$ and cooling in subpolar basin and at $\sim 30 \mathrm{~N}$. This signature of high-latitude $(>50 \mathrm{~N})$ cooling may be also traced in the regression pattern of simulated SST (Fig. 9). This pattern compares well with observations (Figs. 2, 5). The presence of anomalously cold surface water located in the regions of major North Atlantic surface heat transports is consistent with a weakening of the circulation. To verify this hypothesis with modeling results, we used the upper $50 \mathrm{~m}$ meridional North Atlantic heat and water fluxes (Fig. 10) and zonal average North Atlantic MOC associated with the nonlinear trend (EOF1, Fig. 11) simulated by the BCCR model. In the BCCR model, the simulated twentieth century northward heat transport decreases and the bulk of this decrease is linked to a weakening of the northward branch of the circulation. The simulated MOC also slows down, by $\sim 2 \mathrm{~Sv}$, in the warmer climate (Fig. 11). This is consistent with our observational findings; the entire suite of IPCC (2007) models also shows a weakening of the MOC in a warmer climate. All models reproduce successfully (with some differences in details) the observed enhancement of the SLP pattern with a warmer climate (compare Figs. 12 with 5) suggesting that anomalous wind may be an active player in shaping the pattern of North Atlantic cooling north of the mean zero 


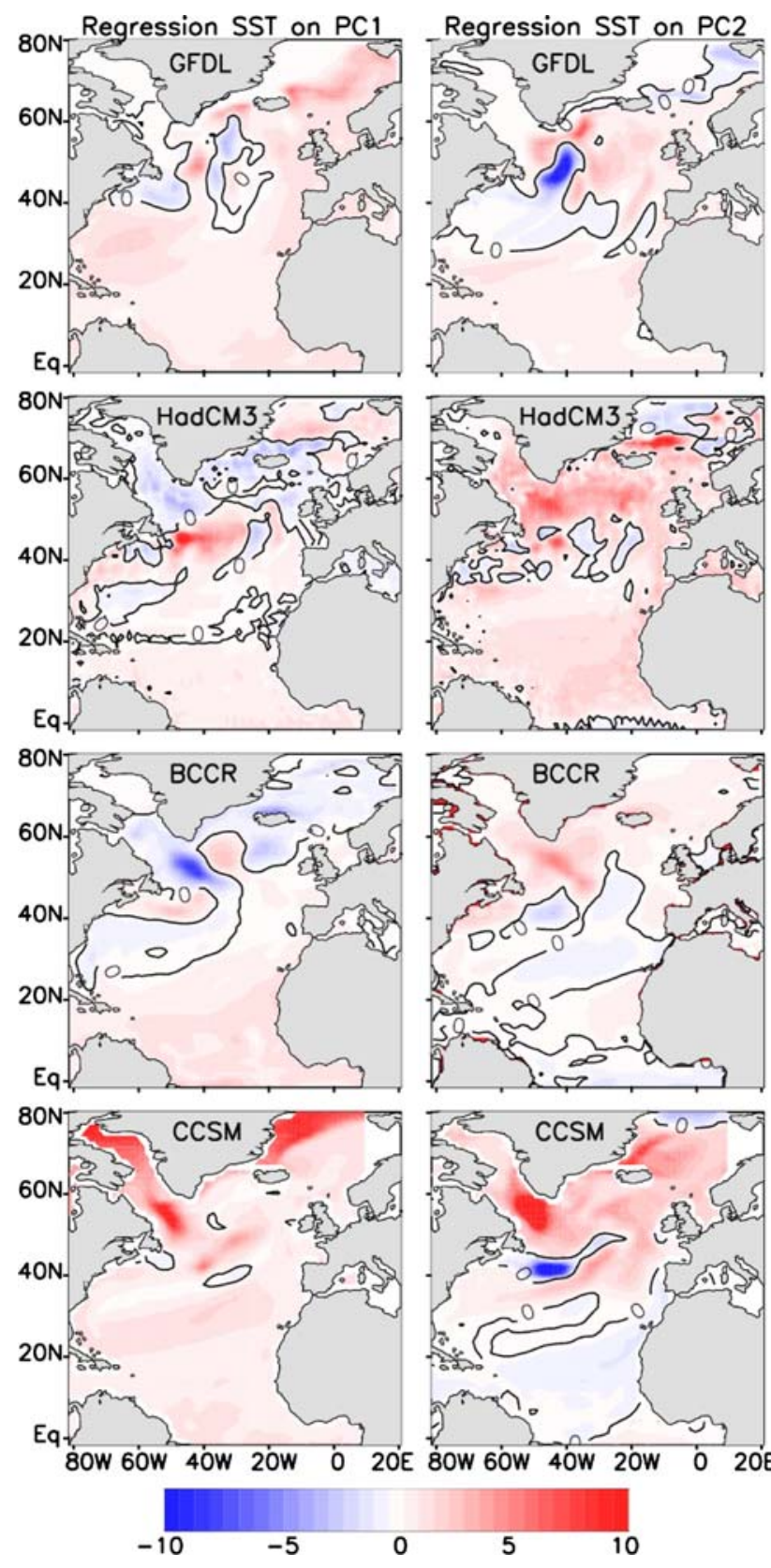

Fig. 9 Regression coefficients of SST $\left({ }^{\circ} \mathrm{C} /{ }^{\circ} \mathrm{C}\right)$ associated with longterm climate change (left column) and the multidecadal variability (right column) from four general circulation models. The maps are constructed by regressing simulated SST on simulated PC1 and PC2. Areas with statistical confidence less than $95 \%$ are left without color

wind stress curl line and warming to the south. Thus, the high-latitude $(>50 \mathrm{~N})$ cooling may partially result from increased wind curl stress driving enhanced upwelling of cold waters at high latitudes and more pumping of warm waters at low latitudes (Fig. 12).

The IPCC models display varying success at simulating features of MDV. The second EOFs with the corresponding PCs of simulated zonal mean water temperature which, according to our observational analysis is associated with the multidecadal mode of variability are shown in Fig. 8 (right). The twentieth century model runs are dominated by the long-term trend as expressed by greater variance explained by EOF1s; as a result the relative role of multidecadal fluctuations is proportionally less in the modeled data than in the observations. The modeled EOF2 patterns bear certain similarities (Fig. 8, right) to the observations. For example, all models show that during the positive phase the northern North Atlantic region $(>50 \mathrm{~N})$ is warmer down to $1,000-1,500 \mathrm{~m}$ and deeper depending on the model. The simulated cold anomaly associated with the intergyre gyre at $\sim 40-45 \mathrm{~N}$ occupies a substantial portion of the ocean interior while the simulated variability in the tropical North Atlantic is not as consistent among the models. The HadCM3 run seems to be the most successful in simulating the observed pattern of multidecadal fluctuations showing opposing anomalies in the upper and lower ocean (compare Figs. 2, 8) and a single-sign basin-wide spatial pattern of MDV in each layer (compare Figs. 5, 9). The BCCR-BCM2.0 simulation of the THC driving these changes is shown in Fig. 11. The EOF2 pattern from BCCR-BCM2.0 compares favorably with our observationbased findings of suppressed (enhanced) circulation in the tropical North Atlantic (intergyre gyre) (with less success in reproducing the subpolar basin) during the positive MDV phase. However, PC2 for BCCR-BCM2.0 MOC appears noisy and contains decadal-scale variations which mask the multidecadal signal. Note that a similar EOF pattern for MDV was obtained by Eden and Willebrand (2001) as a response of the ocean to changes in atmospheric circulation and by Vellinga and $\mathrm{Wu}$ (2004) in a HadCM3 control run as a signature of internal oceanic THC. It has been stressed by Osborn (2004), and our analysis confirms this conclusion, that the observed NAO pattern which is enhanced (suppressed) during the positive (negative) phase of MDV is not well reproduced by all GCMs. For example, the CCSM3.0 simulation shows quite a different SLP pattern (Fig. 12) compared with observations (Fig. 5). Two modeled SLP distributions (HadCM3 and BCCR-BCM2.0) are similar to each other, but look less zonal compared with the observed pattern.

The reasons for inconsistencies between models and observations may be different (see Sect. 6 in depth in Parker et al. 2007) and one of the purposes of using several simulations in this study was to demonstrate this diversity. In this study we have not explored important physical mechanisms like convective ventilation (e.g. Hawkins and Sutton 2007), air-sea interactions (e.g. Timmermann et al. 1998; Bhatt et al. 1998) or internal oceanic THC (e.g. Vellinga and $\mathrm{Wu}$ 2004). However, the modeling results provide support for our observation-based conclusions namely that the climate change-related pattern of regional 
Fig. 10 Meridional upper $50 \mathrm{~m}$ North Atlantic heat flux (PW) simulated by the BCCR model. The dotted black line shows water transport $\left(\mathrm{Sv}=10^{6} \mathrm{~m}^{3} \mathrm{~s}^{-1}\right)$. Note that a general decrease of net heat transport in the twentieth century is due to slowing down of water transport and is consistent with weakening circulation

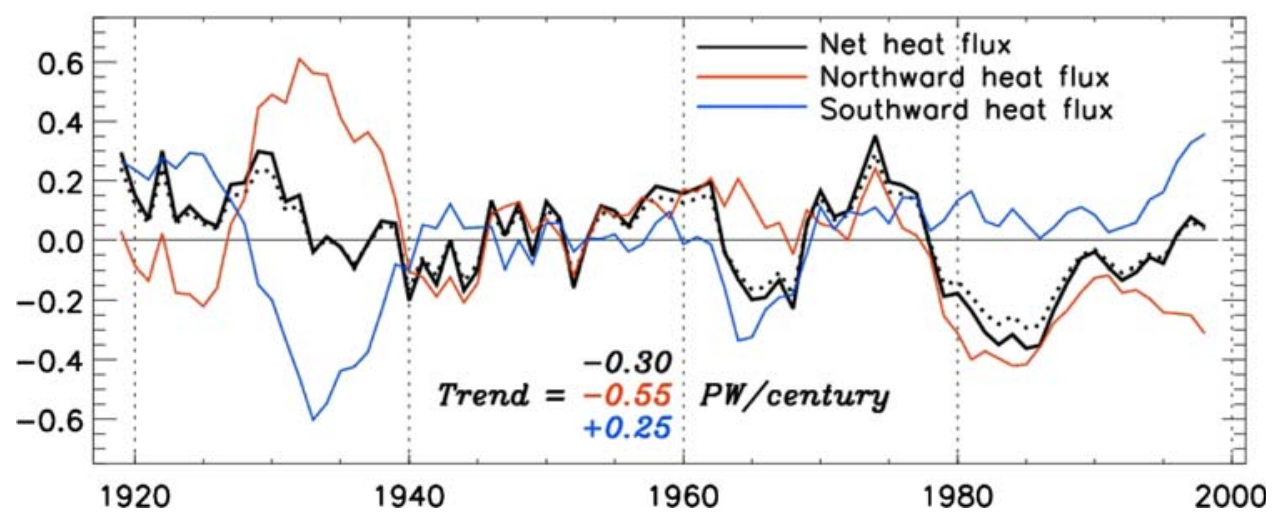

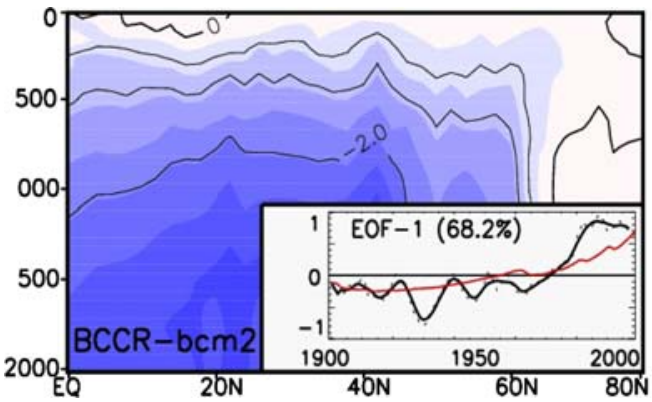

Fig. 11 Patterns of zonal average North Atlantic MOC associated with the nonlinear trend (left column) and multidecadal variability (right column) simulated by BCCR model. The left panel shows EOF-

cooling is associated with major northward heat transports and is consistent with a slowdown of the North Atlantic circulation.

\section{Discussion and conclusions}

\subsection{Long-term trend}

An analysis of observational ocean temperatures complemented with modeling results is used to assess the relative contributions of the long-term trend and large-amplitude multidecadal fluctuations to warming in the North Atlantic. The modal structure of North Atlantic variability derived from observations and modeling may be summarized as follows. The leading mode of oceanic variability captures the long-term non-linear trend which displays an accelerated increase in recent decades and we speculate that it may be related to enhanced radiative forcing. It is still unclear why the zero-lag correlation between PC1 of the zonal mean water temperature and the net radiative forcing is maximum (Fig. 3) with correlations decreasing rapidly with increasing lag. Assuming this is true then one interpretation is that the fast oceanic response to radiative forcing may be due to the strong impact that convective processes have on the formation rate of the North Atlantic

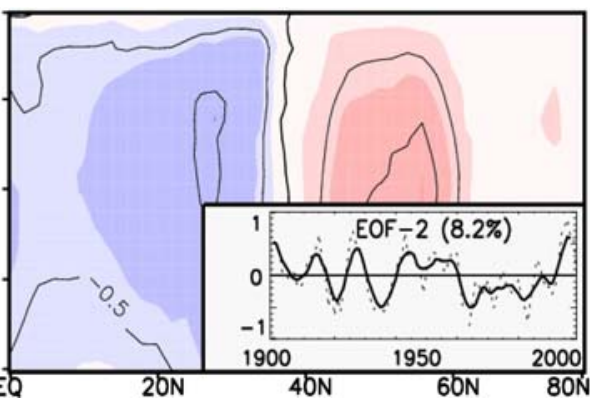

1 (insert shows $\mathrm{PC} 1, \mathrm{~Sv}$, black, and radiative forcing, red). The right panel shows EOF-2 (insert shows PC2, Sv). Weak three-point running mean smoothing is applied to the original modeling data

Intermediate Water in the Labrador Sea (Dickson et al. 1996, 2002; Curry and McCartney 2001; Curry et al. 2003). Convectively-driven Labrador Sea anomalies spread across the northern North Atlantic surprisingly quickly (Sy et al. 1997). Modeling results support the important role of Labrador Sea convection in shaping North Atlantic multidecadal fluctuations (e.g. Jungclaus et al. 2005; Hawkins and Sutton 2007). Another possibility is that the seemingly fast deep-ocean response to radiative forcing may be linked to the barotropic mode excited by the radiative forcing via SSH modulations. However, additional research is necessary to explain this further.

The spatial structure of the leading mode may be expressed in terms of a large-scale horizontal gyre-like circulation. One of the most intriguing features of the longterm warming trend is the presence of anomalously cold water located in the regions of major North Atlantic surface heat transports, including the Gulf Stream-North Atlantic Current system and their poleward continuation, the Norwegian Current, consistent with a slowdown of the North Atlantic circulation. The pattern of North Atlantic cooling north of the mean zero wind stress curl line and warming southward (Fig. 5) also suggests that the signal may partially result from an increased wind stress curl driving increased upwelling of cold waters at high latitudes and more pumping of warm waters at low latitudes. Anomalous 

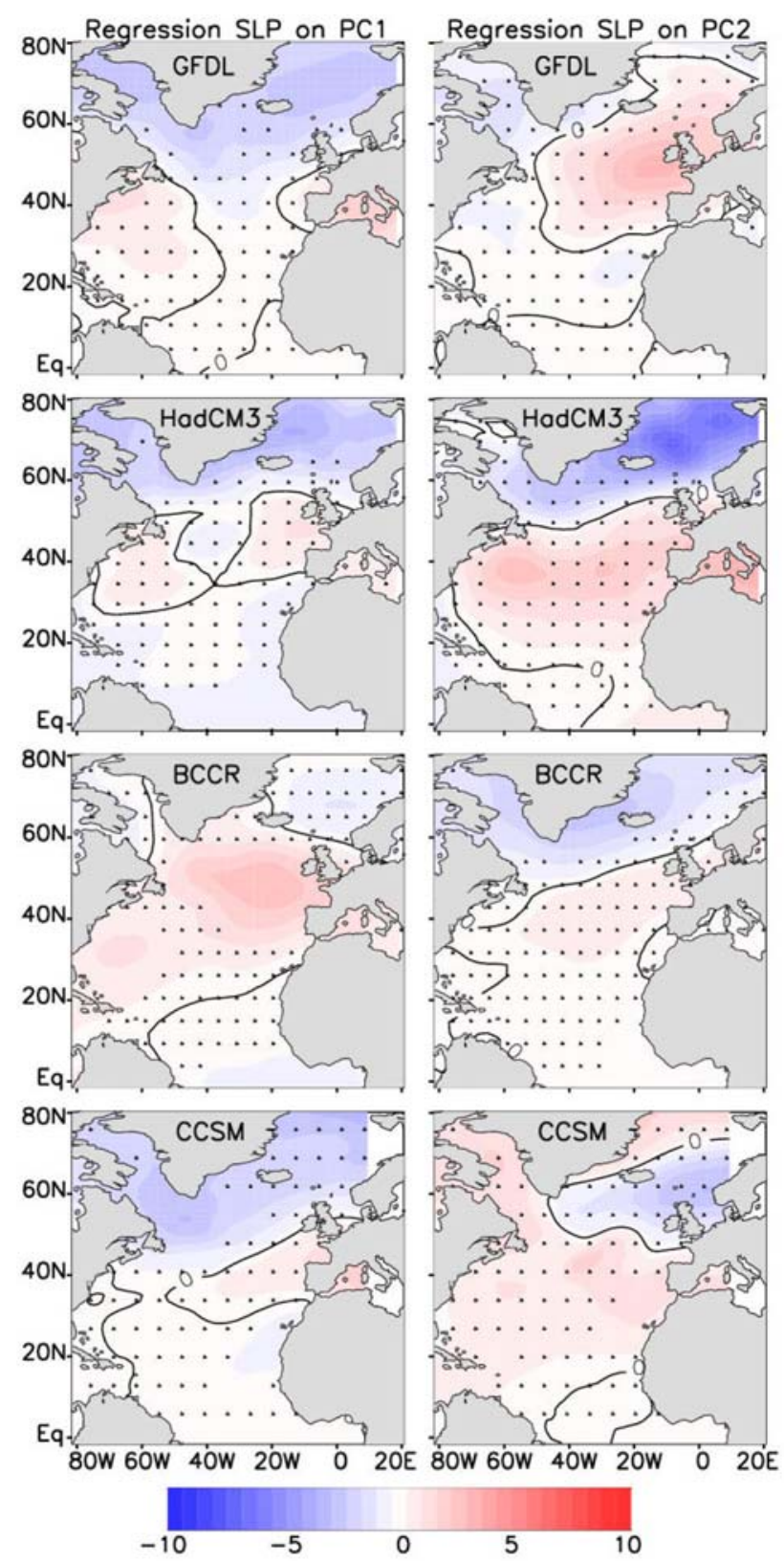

Fig. 12 Regression coefficients of $\operatorname{SLP}\left(\mathrm{mb} /{ }^{\circ} \mathrm{C}\right)$ associated with long-term climate change (left column) and the multidecadal variability (right column) from four general circulation models. The maps are constructed by regressing simulated SLP on simulated PC1 and PC2. Note that PC2 is lagged by 8 years relative to PC2 (SLP leads) reflecting the delayed oceanic response to atmospheric forcing. Areas with statistical confidence less than $95 \%$ are stippled

advection of cold northerly air masses due to changes in atmospheric circulation may play a role as well.

\subsection{Multidecadal variability}

This localized cooling has been masked in recent decades by warming during the positive phase of MDV which represents the second mode of variability. We hypothesize MDV is linked to changes in the intensity of the vertical MOC (note that the models used in this study were limited in their ability to reproduce major features of the observed multidecadal variations). A schematic of the two phases of MDV in the North Atlantic based on a synthesis of published literature and complemented by findings of this study is presented in Fig. 13. This figure should be viewed as a highly schematic, conceptual representation of two states of multidecadal fluctuations, since a dearth of observational data and limitations of present-day GCMs create many uncertainties and controversies in our notion of low-frequency climate fluctuations. In addition, due to the intermittent nature of oceanic variability, there is no static, quasi-stable state as such. However, despite these limitations, Fig. 13 provides useful information distinguishing, conceptually, components of North Atlantic multidecadal fluctuations.

- Temperature and salinity in the upper and lower layers vary in opposition, consistent with the notion of THC, with prolonged periods of basin-wide single-sign warming and salinification (cooling and freshening) in one layer associated with the opposite tendencies in the other layer (Visbeck et al. 2002; Polyakov et al. 2005; Zhang et al. 2007, Figs. 2, 5 from this study).

- Convergence (divergence) of winds (Fig. 3) drives an oceanic downwelling (upwelling) centered at $\sim 45 \mathrm{~N}$ (intergyre gyre, Eden and Willebrand 2001; Marshall et al. 2001a, b) and is characterized by anomalously high (low) SSTs and enhanced (reduced) surface heat fluxes from the ocean to the atmosphere during the positive (negative) phase of MDV (e.g. Marshall et al. 2001a, b, see also Fig. 5).

- Changes in the density structure between the warm and cold phases of MDV act in an opposing way on the ocean circulation by enhancing (suppressing) the intergyre gyre centered around $\sim 45 \mathrm{~N}$ while at the same time weakening (strengthening) the northeastern flow in the northern $(\sim 52-65 \mathrm{~N})$ North Atlantic and in the tropics $(<30 \mathrm{~N})$ (Häkkinen and Rhines 2004; Bryden et al. 2005; Fig. 6).

- During the positive, or warm (negative, or cold) phase, there is an enhancement (slowing down) of the MOC including the Gulf Stream and southern part of the North Atlantic Current (e.g. Figs. 6, 7).

- These changes (we speculate) in the MOC between warm (cold) MDV phases may be closely related to enhanced (suppressed) deep water convection in the Labrador Sea and weakened (strengthened) convection in the Greenland Sea (e.g. Dickson et al. 1996, 2002; Visbeck et al. 2002; Schlosser et al. 1991; Curry et al. 1998). 


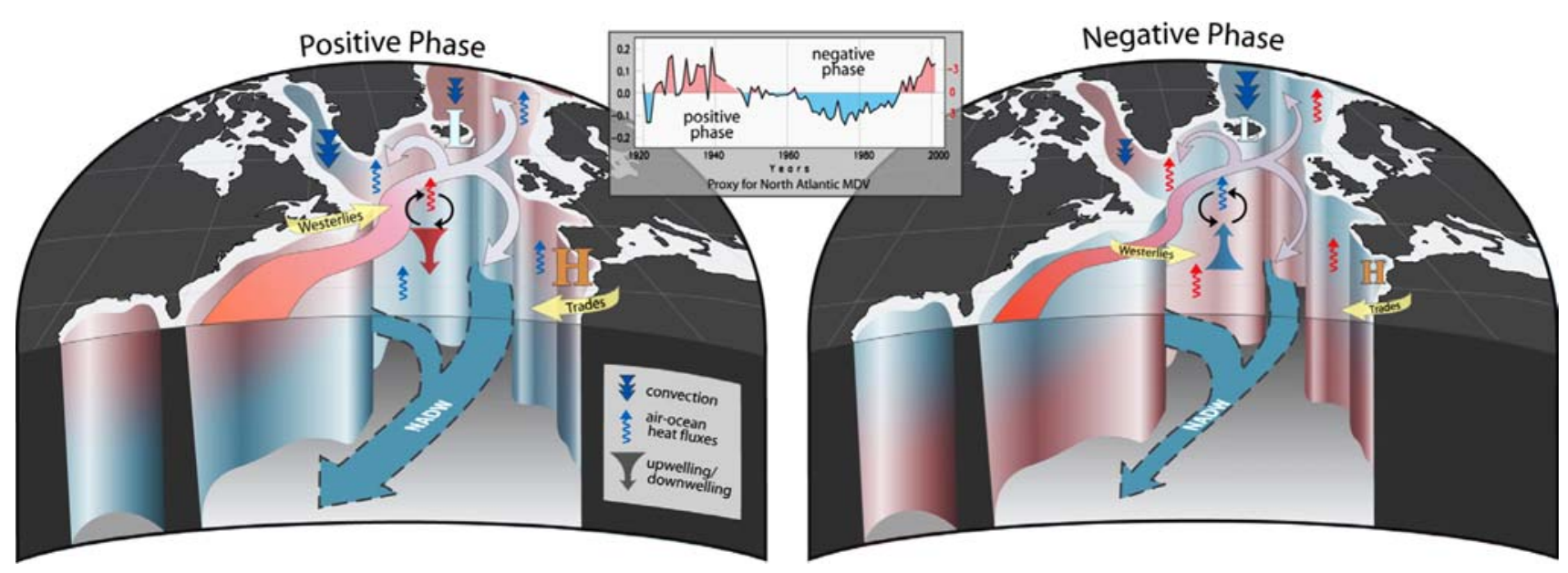

Fig. 13 Schematic depicting the two states of multidecadal variability in the North Atlantic is based upon previous studies in conjunction with current findings (see Sect. 4 for details)

- Outside the intergyre gyre region, air-ocean interactions lead to reduced (enhanced) heat fluxes from ocean to atmosphere during positive (negative) phases of MDV (e. g. Delworth and Greatbatch 2000, Fig. 5 from this study).

- The well-developed atmospheric pressure centers, evident during positive phases of MDV result in intensified westerlies and trade winds (e.g. Kushnir 1994; Dickson et al. 1996; Shabbar et al. 2001; Zhang et al. 2007) and, likely, an enhanced wind-driven component of the ocean circulation.

There is extended literature devoted to mechanisms responsible for the shift from one phase of MDV to another (see, for example, in depth discussion in Marshall et al. 2001a, b). Long-term internal oceanic circulation seems to play a fundamental role in shaping climate variability on time scales from several decades to centuries. For example, our analysis demonstrates that the recent warming over the North Atlantic $(0-3,000 \mathrm{~m})$ is linked to both long-term (including anthropogenic) climate change and MDV, and the latter accounts for $\sim 60 \%$ of warming in the North Atlantic since 1970 . We speculate, however that the combined effect of long-term climate change and a shift to the negative, or cool, phase of MDV would result in anomalously cold North Atlantic with a corresponding climate impact in Europe.

\subsection{Concluding remarks}

Finally, we note that since the North Atlantic Ocean plays a crucial role in the global thermohaline circulation, multidecadal fluctuations must be taken into account when assessing long-term climate change and variability in the North Atlantic as well as over broader spatial scales. Anthropogenic climate change may be amplified or masked by multidecadal variations and these modes of variability can only be separated when the mechanisms governing them are better understood. An important caveat is that we have treated the mechanisms associated with the long term-trend and MDV separately while in reality increasing greenhouse gases likely also projects onto the multidecadal mode of variability. Advances in modeling and theory as well as continued observations are required in order to develop a deeper understanding of North Atlantic variability at multiple time scales. This will be a nontrivial task due largely to the poorly defined character of this low-frequency variability and the changing relationship with large-scale climate parameters like the NAO (Polyakova et al. 2006).

Acknowledgments This study was supported by JAMSTEC (IP, UB, EP and XZ), NOAA/CIFAR (IP and XZ), NSF grants (IP, VA, and UB) and Stanford University (EP). We thank J. Moss for help with the graphics and K. Bryan, D. Newman, J. Walsh and J. M. Wallace for insightful comments. We really appreciate help of anonymous reviewers.

Open Access This article is distributed under the terms of the Creative Commons Attribution Noncommercial License which permits any noncommercial use, distribution, and reproduction in any medium, provided the original author(s) and source are credited.

\section{Appendix}

\section{Robustness of analyses}

Sensitivity of EOF analysis to data quality

Insufficient observations place constraints on our ability to elucidate the spatial and temporal patterns of North Atlantic Ocean long-term variability. For example, the 
relatively short instrumental record makes it difficult to draw firm, statistically-sound conclusions about the exact time scales of multi-decadal variability. The spatial coverage of available observational data deteriorates toward the earlier part of the twentieth century (for a detailed discussion see (Polyakov et al. 2005), see also Fig. 1). Inadequate spatial coverage may become an obstacle to understanding the critical mechanisms governing the transition from one phase of multi-decadal variability to another. Indeed, the impact of inadequate spatial coverage can be seen in the computed annual anomalies presented by the PC1 and PC2 time series (Figs. 2, 4) which are characterized by larger annual variations in the earlier parts of the records; this may impact estimates of thermal anomaly magnitudes. However, despite the problems posed by the scarcity of observations from the earlier part of the twentieth century, spatially averaged estimates presented in this study provide valuable insight into North Atlantic variability. Consistent results (Fig. 3) support the robustness of these composite time series.

Sensitivity of the EOF analysis to outliers in the "raw" temperature data was evaluated by performing a set of experiments, in which EOFs and PCs were computed by omitting temperature anomalies exceeding 2.5 , $3, \ldots, 4.5$ local temporal standard deviations (SD). Results presented in the paper are based on 4SD-filtering of the outliers (named the "standard case"). PCs one and two based on other levels of filtering are highly correlated $(R>0.90)$ with an insignificant (within 7\%) difference of their standard deviations compared with the standard case. The sensitivity of the composite zonal temperature transects and derived EOFs to removal of the seasonal cycle (de-seasoning) and to spatial averaging procedures is a measure of the robustness of our analysis. For example, statistical estimates based on different methods of calculating zonal means within each latitudinal belt (simple spatial averaging vs. distanceweighted averaging) do not result in significantly different modes of variability: the leading PCs are well correlated (for PC1 $R=0.98$; for PC2 $R=0.97$ ) and the $\mathrm{SD}$ of these records are also reasonably close (for both PC1 and PC2 SD change is within 5\%). The impact of removing the seasonal cycle was also investigated. Zonal average temperature transects and EOFs were computed using ocean temperature measurements with and without the removal of monthly means (for details on climatology we refer to (Polyakov et al. 2005)) and the results were compared. Removal of the seasonal cycle had little impact on the computed EOFs: the two leading PCs are well correlated $(R>0.95)$ and their SDs differ by 9 and $6 \%$, correspondingly (probably, because of the normalization of temperature by standard deviations and correlation EOF analysis).
To further assure the robustness of the EOF analysis we evaluated the sensitivity of the EOFs to gaps in the data. This analysis demonstrates the robustness in the EOFbased estimates. In these experiments we eliminated points where data coverage in time was less than $40,50,60$, and $70 \%$. Despite this severe condition (for example, for the $70 \%$ case only $53 \%$ of points remained for the EOF analysis), correlation of these time series with the 4SD-based PCs yield $R>0.85$ for $\mathrm{PC} 1$ and $R>0.73$ for $\mathrm{PC} 2$ with $\mathrm{SD}$ estimates within 70 and $76 \%$ for $\mathrm{PC} 1$ and $\mathrm{PC} 2$, respectively. EOFs were also calculated using data from 1950 onward, to ensure that sparce data in the early part of the resord did not contaminate the EOFs. We find that the spatial (EOF) and temporal (PC) patterns of the two leading modes remained intact (not shown).

The major features displayed by the computed EOFs and PCs cannot be solely explained by random noise in the observational data. To verify this, we added Gaussian noise to the "raw" ocean temperatures. This random noise was calculated using zero mean and $0.1^{\circ} \mathrm{C}$ variance based on 98\% confidence intervals of North Atlantic composite annual water temperature anomalies (Polyakov et al. 2005). Note that this level of noise well exceeds instrumental errors. The resulting noisy data were used to calculate zonal mean anomalies and their EOFs. This process was repeated 500 times. We found that because of the large number of observations used in this study, the error bars estimated as maximum annual departures from the "standard" PCs are practically indistinguishable from the PCs (except for several peak points of the records) and are not shown. These estimates suggest that the leading EOF patterns of the North Atlantic long-term climate change (PC1) and multidecadal fluctuations (PC2) cannot be attributed to random noise.

\section{Separation of modes of variability}

Results of EOF analysis presented in the text are based on smoothed data (9-year running mean filter was used). Experiments employing a varying number of weights used in the running mean indicate that the smoothing had little effect on the spatial EOF patterns as evidenced from high pattern correlation $R=0.89 / 0.77$ between EOF1/EOF2 computed using original and 9-year filtered data. However, filtering of the high-frequency signal allowed us to increase substantially the level of variance explained by EOFs. The three leading EOFs (smoothed data) are significantly separated from each other based on the North et al. (1982) test, they explain 28.1, 20.2 and $8.6 \%$ of variance (Figs. 14, 15) and account for more than $50 \%$ of total variance (Fig. 15).

We further show that the leading EOFs of the observed zonal mean water temperature are not in a quadrature relationship (like EOFs presented in Hawkins and Sutton 
Fig. 14 The three leading EOFs of zonal average filtered North Atlantic Ocean temperature. Inserts show corresponding PCs $\left({ }^{\circ} \mathrm{C}\right.$, black). Radiative forcing is shown in red

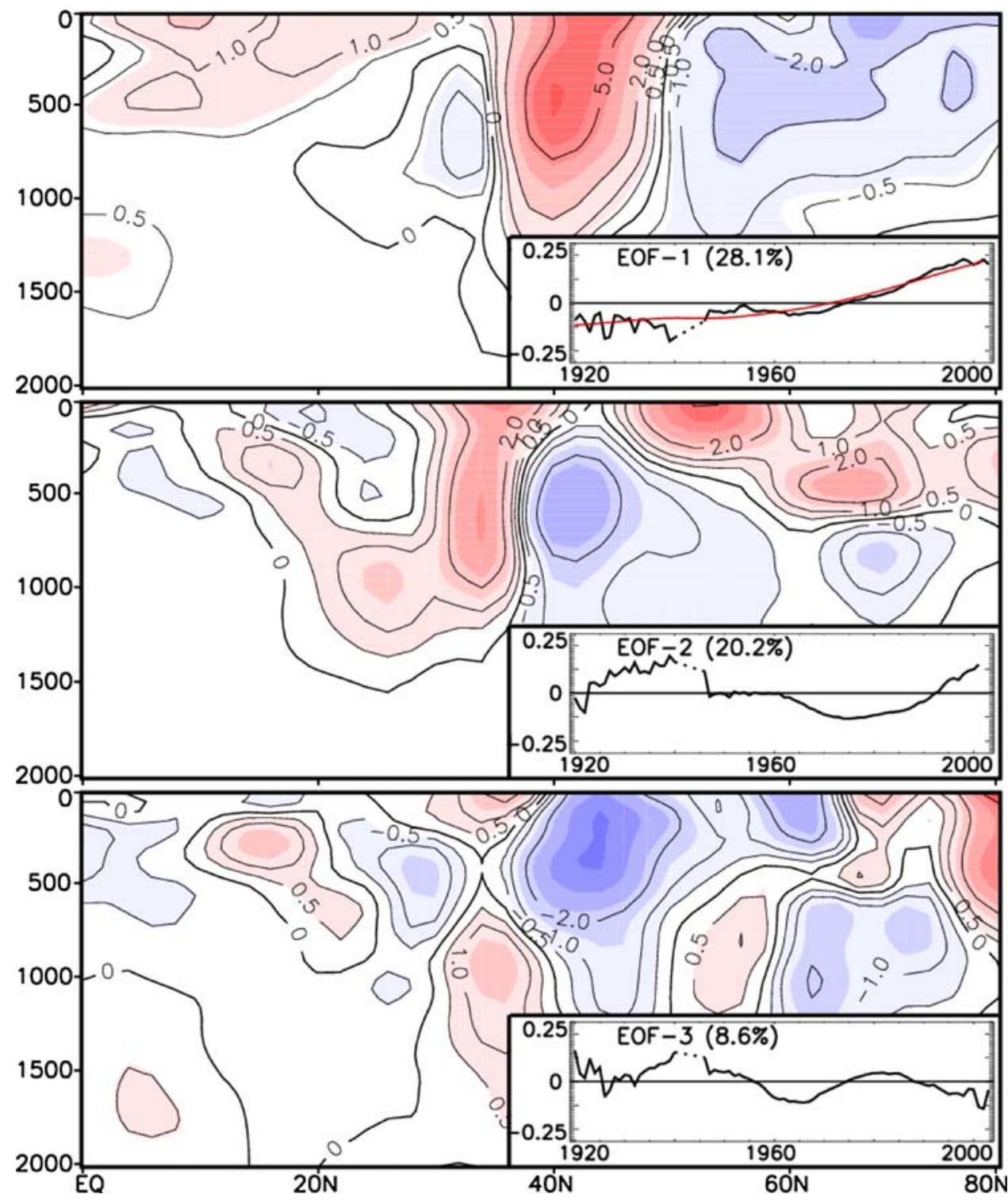

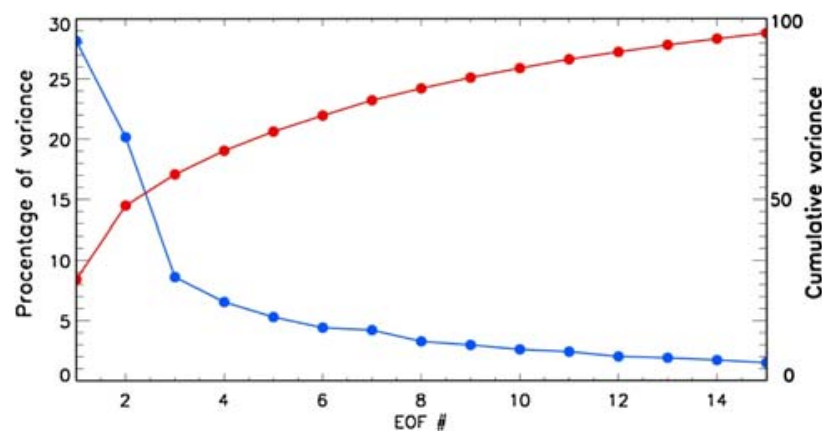

Fig. 15 Blue line and left hand axis scale: the eigenspectrum for the 15 leading EOFs of zonal mean water temperature. Red line and right hand axis scale: cumulative fraction of variance explained

(2007)). Cross-correlation analysis of unfiltered PC1 and PC2 showed no strong positive correlation within a 0 30 year lag range suggesting that the leading PCs do not exhibit a moving pattern. To further illustrate this point, we present phase space diagrams for the PC1-PC2 and PC2PC3 pairs (Fig. 16). With the limited time covered by observational data, PC1 against PC2 does not contain any circular pattern while a two-loop pattern is spanned by PC2PC3 (the latter is associated with two peaks in PC2 and three peaks in PC3) suggesting that the pairs of the PCs do not exhibit a quadrature relationship. We extended this analysis by applying rotated EOFs using the varimax algorithm (eofunc_varimax function from NCL software package, Wilks 2005). Rotation was performed after scaling all eigenvectors by the corresponding eigenvalues. Comparison of EOFs computed using standard and "rotated" algorithms (both applied to unfiltered data) showed reasonably high statistically significant correlation of $R=0.77$ for EOF $1, R=0.68$ for EOF2 and $R=0.71$ for EOF3 suggesting that the computed EOFs do not exhibit a moving pattern. 

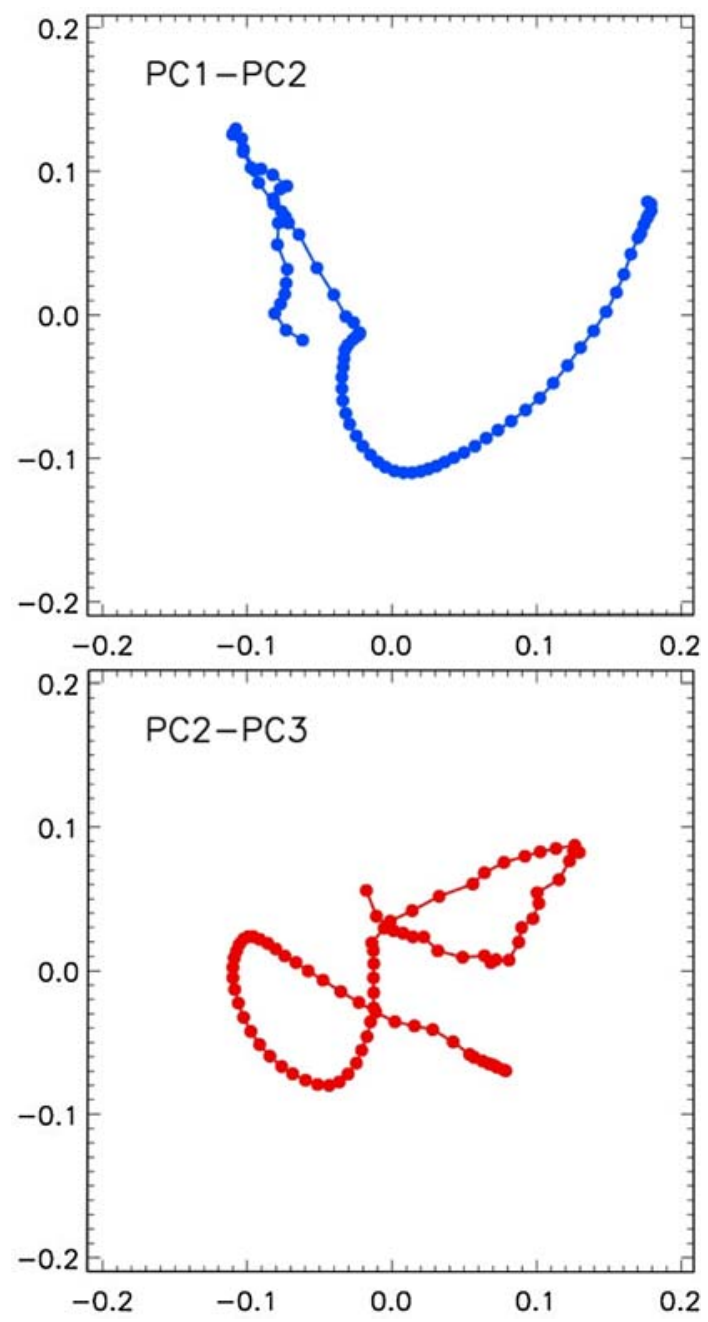

Fig. 16 Phase space diagram showing patterns spanned by PC1-PC2 and PC2-PC3. Lack of a circular pattern spanned by PC1-PC2 and a two-loop pattern spanned by PC2-PC3 suggests that the PC pairs do not exhibit a quadrature relationship

Table 2 Trends $\left({ }^{\circ} \mathrm{C} /\right.$ decade) of principal components (PCs) of the EOF analysis of zonal average North Atlantic water temperature, correlation between trends and PCs, and Cox and Stuart test accepting ("Yes") or rejecting ("No") at 0.05 significance level hypothesis of good fit of linear trend to corresponding PC

\begin{tabular}{llll}
\hline & Trend & Correlation & Cox and Stuart test \\
\hline PC1 & $0.031 \pm 0.006$ & 0.89 & Yes \\
PC2 & $0.006 \pm 0.007$ & 0.38 & No \\
\hline
\end{tabular}

We also present evidence that PC1 and PC2 are statistically very different. Our analysis demonstrates that while PC1 may be approximated very well by linear trend, this approximation is not a good fit for the PC2 (Table 2). First, PC1 has a statistically significant trend whereas PC2 does not. Secondly, PC1 is well correlated with its linear trend and PC2 is not. Moreover, applying the Cox and Stuart goodness of fit test indicates that a linear trend is a good fit for PC1 while it is not for PC2. Thus, this analysis supports the interpretation that two distinctly different patterns of variability expressed by EOFs/PCs may be associated with the long-term trend and multi-decadal variations in the North Atlantic Ocean temperature.

\section{References}

Alexeev VA (2003) Sensitivity to $\mathrm{CO}_{2}$ doubling of an atmospheric GCM coupled to an oceanic mixed layer: a linear analysis. Clim Dyn 20:775-787

Alexeev VA, Langen PL, Bates JR (2005) Polar amplification of surface warming on an aquaplanet in "ghost forcing" experiments without sea ice feedbacks. Clim Dyn. doi:10.1007/ s00382-005-0018-3

Barnett TP, Pierce DW, AchutaRao KM, Gleckler PJ, Santer BD, Gregory JM, Washington WM (2005) Penetration of humaninduced warming into the world's oceans. Science 309:284-287

Barnston AG, Livezey RE (1987) Classification, seasonality and persistence of low-frequency atmospheric circulation patterns. Mon Weather Rev 115(6):1083-1126

Bengtsson L, Semenov VA, Johannessen OM (2004) The early twentieth-century warming in the Arctic-a possible mechanism. J Clim 17:4045-4057

Bhatt US, Alexander MA, Battisti DS, Houghton DD, Keller LM (1998) Atmosphere-ocean interaction in the North Atlantic: near surface climate variability. J Clim 11:1615-1632

Bjerknes J (1964) Atlantic air-sea interaction. Adv Geophys 20:1-82

Boyer TP et al. (2006) World Ocean Database 2005. In: S. Levitus (ed) NOAA Atlas NESDIS 60. U.S. Government Printing Office, Washington, DC, $190 \mathrm{pp}$

Bryden HL, Longworth HR, Cunningham SA (2005) Slowing of the Atlantic meridional overturning circulation at $25^{\circ} \mathrm{N}$. Nature 438:655-657

Cane MA et al (1997) Twentieth-century sea surface temperature trends. Science 275:957-960

Cunningham SA et al (2007) Temporal variability of the Atlantic meridional overturning circulation at $26.5^{\circ} \mathrm{N}$. Science $317: 935$ 938

Curry RG, McCartney MS, Joyce TM (1998) Oceanic transport of subpolar climate signals to mid-depth subtropical waters. Nature 391:575-577

Curry RG, Dickson RR, Yashayaev I (2003) A change in the freshwater balance of the Atlantic Ocean over the past four decades. Nature 426:826-829

Curry RG, McCartney MS (2001) Ocean gyre circulation changes associated with the North Atlantic oscillation. J Phys Oceanogr 31:3374-3400

Delworth TL, Manabe S, Stouffer RJ (1993) Interdecadal variations of the thermohaline circulation in a coupled ocean-atmosphere model. J Clim 6:1993-2011

Delworth TL, Greatbatch RJ (2000) Multidecadal thermohaline circulation variability driven by atmospheric surface flux forcing. J Clim 13:1481-1495

Delworth TL, Mann ME (2000) Observed and simulated multi-decadal variability in the Northern Hemisphere. Clim Dyn 16:661-676

Deser C, Blackmon M (1993) Surface climate variations over the North Atlantic Ocean during winter: 1900-1989. J Clim 6:1743-1753

Dickson RR, Lazier J, Meincke J, Rhines P, Swift J (1996) Long-term coordinated changes in the convective activity of the North Atlantic. Prog Oceanogr 38:241-295 
Dickson RR et al (2002) Rapid freshening of the deep North Atlantic Ocean over the past four decades. Nature 416:832-837

Divine DV, Dick C (2006) Historical variability of sea ice edge position in the Nordic Seas. J Geophys Res 111. doi:10.1029/ 2004JC002851

Eden C, Jung T (2001) North Atlantic interdecadal variability: ocean response to the North Atlantic oscillation (1865-1997). J Clim 14:676-691

Eden C, Willebrand J (2001) Mechanism of interannual to decadal variability on the North Atlantic circulation. J Clim 14:22662280

Enfield DB, Mestas-Nunez AM, Trimble PJ (2001) The Atlantic multidecadal oscillation and its relation to rainfall and river flows in the continental US. Geophys Res Lett 28:2077-2080

Folland CK, Palmer TN, Parker DE (1986) Sahel rainfall and worldwide sea temperatures. Nature 20:602-606

Fritzsche D, Schütt R, Meyer H, Miller H, Wilhelms F, Opel T, Savatyugin LM (2005) A 275 year ice core record from Akademii Nauk ice cap, Severnaya Zemlya, Russian Arctic. Ann Glaciol 42:361-366

Gray ST, Graumlich LJ, Betancourt JL, Pedersen GT (2004) A treering based reconstruction of the Atlantic Multidecadal Oscillation since 1567 A.D. Geophys Res Lett 31:L12205. doi:10.1029/ 2004GL019932

Häkkinen S (1999) Variability of the simulated meridional heat transport in the North Atlantic for the period 1951-1993. J Geophys Res 104:10991-11007

Häkkinen S, Rhines P (2004) Decline of subpolar North Atlantic circulation during the 1990s. Science 304:555-559

Hawkins E, Sutton R (2007) Variability of the Atlantic thermohaline circulation described by three-dimensional empirical orthogonal functions. Clim Dyn 29:745-762. doi:10.1007/s00382007-0263-8

Intergovernmental Panel on Climate Change (2007) IPCC Fourth Assessment Report. Climate change 2007: the physical science basis. Cambridge

Jungclaus JH, Haak H, Latif M, Mikolajewicz U (2005) Arctic-North Atlantic interactions and multi-decadal variability of the meridional overturning circulation. J Clim 18:4013-4031

Kaplan A et al (1998) Analyses of global sea surface temperature 1856-1991. J Geophys Res 103:18567-18589

Kushnir Y (1994) Interdecadal variations in North Atlantic sea surface temperature and associated atmospheric conditions. J Clim 7:141-157

Knight JR, Allan RJ, Folland CK, Vellinga M, Mann ME (2005) A signature of persistent thermohaline circulation cycles in observed climate. Geophys Res Lett 32:L20708. doi:10.1029/ 2005GL024233

Kravtsov S, Spannagle C (2008) Multidecadal climate variability in observed and modeled surface temperatures. J Clim 21:11041121

Langen PL, Alexeev VA (2007) Polar amplification as a preferred response in an aquaplanet GCM. Clim Dyn. doi:10.1007/s00382006-0221-x

Latif M (1998) Dynamics of interdecadal variability in coupled ocean-atmosphere models. J Clim 11:602-624

Latif M, Boning C, Willebrand J, Biastoch A, Dengg J, Keenlyside N, Schweckendiek U (2006) Is the thermohaline circulation changing? J Clim 19:4631-4637

Levitus S, Antonov JI, Boyer TP, Stephens C (2000) Warming of the World Ocean. Science 287:2225-2229

Levitus S, Antonov JI, Boyer TP (2005) Warming of the World Ocean, 1955-2003. Geophys Res Lett 32:L02604. doi:10.1029/ 2004GL021592

Mann ME, Emanuel KA (2006) Atlantic hurricane trends linked to climate change. Eos 87(24): 233,238,241
Marshall J, Johnson H, Goodman J (2001a) A study of the interaction of the North Atlantic oscillation with ocean circulation. J Clim 14:1399-1421

Marshall J, Kushnir Y, Battisti D, Chang P, Czaja A, Dickson R, Hurrell J, McCartney M, Saravanan R, Visbeck M (2001b) Review: North Atlantic climate variability: phenomena, impacts and mechanisms. Int J Climatol 21:1863-1898

North GR, Bell TL, Cahalan RF, Moenig FJ (1982) Sampling errors in the estimation of empirical orthogonal functions. Mon Weather Rev 110:669-706

Osborn TJ (2004) Simulating the winter North Atlantic oscillation: the roles of internal variability and greenhouse gas forcing. Clim Dyn 22:605-623

Overland JE, Spillane MC, Soreide NN (2004) Integrated analysis of physical and biological pan-Arctic change. Clim Change 63:291-322

Parker D, Folland C, Scaife A, Knight J, Colman A, Baines P, Dong B (2007) Decadal to multidecadal variability and the climate change background. J Geophys Res 112:D18115. doi:10.1029/ 2007JD008411

Peterson B, McClelland J, Holmes M, Curry R, Walsh J, Aagaard K (2006) Acceleration of the Arctic and Subarctic freshwater cycle. Science 313:1061-1066

Polyakov IV et al (2005) Multidecadal variability of North Atlantic temperature and salinity during the 20th century. J Clim 18(21):4562-4581

Polyakov IV, Alexeev VA, Belchansky GI, Dmitrenko IA, Ivanov V, Kirillov S, Korablev A, Steele M, Timokhov LA, Yashayaev I (2008) Arctic Ocean freshwater changes over the past 100 years and their causes. J Clim 21(2):364-384

Polyakova EI, Journel A, Polyakov IV, Bhatt US (2006) Changing relationship between the North Atlantic oscillation index and key North Atlantic climate parameters. Geophys Res Lett 33: L03711. doi:10.1029/2005GL024573

Schlesinger ME, Ramankutty N (1994) An oscillation in the global climate system of period 65-70 years. Nature 367:723726

Schlosser P, Bonisch G, Rhein M, Bayer R (1991) Reduction of deepwater formation in the Greenland Sea during the 1980s: evidence from tracer data. Science 251:1054-1056

Schott FA, Fischer J, Dengler M, Zantopp R (2006) Variability of the deep western boundary current east of the Grand Banks. Geophys Res Lett 33: L21S07. doi:10.1029/2006GL 026563

Shabbar A, Huang J, Higuchi K (2001) The relationship between the wintertime North Atlantic oscillation and blocking episodes in the North Atlantic. Int J Climatol 21:355-369

Stocker TF, Mysak LA (1992) Climatic fluctuations on the century time scale: a review of high-resolution proxy data and possible mechanisms. Clim Change 20:227-250

Sy A, Rhein M, Lazier JRN, Koltermann KP, Meincke J, Putzka A, Bersch M (1997) Surprisingly rapid spreading of newly formed intermediate waters across the North Atlantic Ocean. Nature 386:675-679

Timmermann A, Latif M, Voss R, Grotzner A (1998) Northern Hemispheric interdecadal variability: a coupled air-sea mode. J Clim 11:1906-1931

Trenberth KE, Paolino DA (1980) The northern hemisphere sea-level pressure data set: trends, errors and discontinuities. Mon Wea Rev 108:855-872

Trenberth KE, Shea DJ (2006) Atlantic hurricanes and natural variability on 2005. Geophys Res Lett 33:L12704. doi:10.1029/ 2006GL026894

Vellinga M, Wu P (2004) Low-latitude freshwater influence on centennial variability of the Atlantic thermohaline circulation. J Clim 17:4498-4511 
Visbeck M et al. (2002) The ocean's response to North Atlantic oscillation variability. In: J Hurrell, Y Kushnir, G Ottersen, M Visbeck (eds) The North Atlantic oscillation: climate significance and environmental impact. Geophysical monograph series, vol 134. AGU, Washington, pp 113-146

Wilks DS (2005) Statistical methods in the atmospheric sciences, 2nd edn. Academic Press, Dublin, $648 \mathrm{p}$

Zhang R, Delworth TL, Held IM (2007) Can the Atlantic Ocean drive the observed multidecadal variability in Northern Hemisphere mean temperature? Geophys Res Lett 34:L02709. doi:10.1029/ 2006GL028683

Zhang R (2007) Anticorrelated multidecadal variations between surface and subsurface tropical North Atlantic. Geophys Res Lett 34:L12713. doi:10.1029/2007GL030225

Zhang X, Walsh JE, Zhang J, Bhatt US, Ikeda M (2004) Climatology and interannual variability of Arctic cyclone activity, 19482002. J Clim 17:2300-2317 